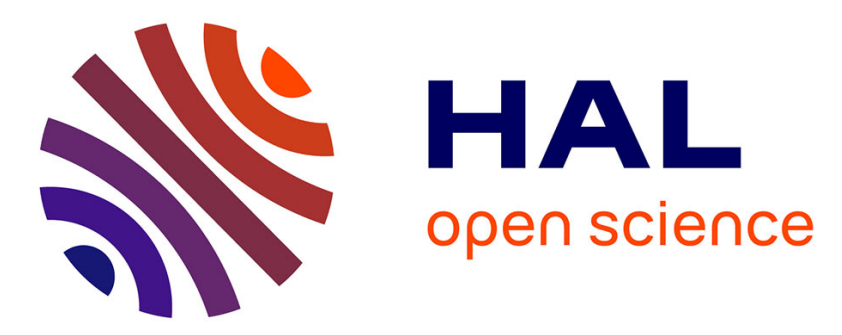

\title{
Ruthenium-Grafted Vinylhelicenes: Chiroptical Properties and Redox Switching
}

Monika Srebro, Emmanuel Anger, Barry Moore ii, Nicolas Vanthuyne, Christian Roussel, Régis Réau, Jochen Autschbach, Jeanne Crassous

\section{To cite this version:}

Monika Srebro, Emmanuel Anger, Barry Moore ii, Nicolas Vanthuyne, Christian Roussel, et al.. Ruthenium-Grafted Vinylhelicenes: Chiroptical Properties and Redox Switching. Chemistry - A European Journal, 2015, 21 (47), pp.17100-17115. 10.1002/chem.201502237 . hal-01212686

HAL Id: hal-01212686

https://hal-univ-rennes1.archives-ouvertes.fr/hal-01212686

Submitted on 2 Jun 2016

HAL is a multi-disciplinary open access archive for the deposit and dissemination of scientific research documents, whether they are published or not. The documents may come from teaching and research institutions in France or abroad, or from public or private research centers.
L'archive ouverte pluridisciplinaire HAL, est destinée au dépôt et à la diffusion de documents scientifiques de niveau recherche, publiés ou non, émanant des établissements d'enseignement et de recherche français ou étrangers, des laboratoires publics ou privés. 


\title{
Ruthenium-grafted vinylhelicenes: chiroptical properties and redox switching
}

\author{
Monika Srebro, ${ }^{[\mathrm{a}]}$ Emmanuel Anger, ${ }^{[\mathrm{b}]}$ Barry Moore, II, ${ }^{[\mathrm{c}]}$ Nicolas Vanthuyne, ${ }^{[\mathrm{d}]}$ Christian \\ Roussel, ${ }^{[d]}$ Régis Réau, ${ }^{[b]}$ Jochen Autschbach, ${ }^{*[c]}$ and Jeanne Crassous ${ }^{*[b]}$
}

\begin{abstract}
The properties of mono- and bis-Ruvinyl[6]helicene complexes ( $\mathbf{2} \mathbf{a}$ and $\mathbf{2 b}$, respectively), recently synthesized using molecular engineering of helicenes based on the grafting of lateral organometallic substituents on the $\pi$-helical backbone via a vinyl bridge, are presented in detail. These helicene derivatives are thoroughly characterized, with special attention given to their chiroptical properties and redox switching activity. The UVvis and electronic circular dichroism (ECD) spectra of $P$ and $M$ enantiopure species, both in neutral and oxidized states $\left([\mathbf{2 a}]^{+},[\mathbf{2 b}]^{+}\right.$, and $\left.[\mathbf{2 b}]^{2+}\right)$ are analyzed with the aid of quantum-chemical calculations. The extended $\pi$-conjugation
\end{abstract}

facilitated by the vinyl moiety, clearly visible in the electronic structures of $\mathbf{2} \mathbf{a}, \mathbf{b}$, introduces new active bands in the ECD spectra that lead in consequence to a significant increase in optical rotation of Ru-vinylhelicenes compared to the organic precursors. The vibrational circular dichroism (VCD) spectra were measured and calculated for both organic and organometallic species and constitute the first examples of VCD for metal-based helicene derivatives. Finally, the redox-triggered chiroptical switching activity of $\mathbf{2 a , b}$ is examined in detail using ECD spectroscopy. The modifications of the ECD spectra in the UV-vis and NIR region are well reproduced and rationalized by theory.

\section{Introduction}

Helicene derivatives ${ }^{[1]}$ are known to display large-magnitude chiroptical properties and appealing photophysical and electronic features due to their inherent helical chirality combined with extended $\pi$-conjugation. The systems attract therefore a great interest for many optoelectronic applications such as for chiral luminescent materials, ${ }^{[2]}$ transistors, ${ }^{[3 a]}$ sensors, ${ }^{[3 b]}$ chiroptical switches, ${ }^{[4]}$ or nonlinear optical absorbers. ${ }^{[5]}$ The main challenge for the development of [n]helicenes towards functional materials is the discovery of efficient synthetic routes and simple strategies

[a] Dr. M. Srebro

Department of Theoretical Chemistry, Faculty of Chemistry Jagiellonian University, R. Ingardena 3, 30-060 Krakow (Poland)

[b] Dr. E. Anger, Prof. R. Réau, Dr. J. Crassous Institut des Sciences Chimiques de Rennes UMR 6226, CNRS Université de Rennes 1, Campus de Beaulieu, 35042 Rennes Cedex (France) E-mail: jeanne.crassous@univ-rennes1.fr

[c] Barry Moore, II, Prof. J. Autschbach

Department of Chemistry, 312 Natural Sciences Complex University at Buffalo, State University of New York Buffalo, NY 14260-3000 (USA)

Email: jochena@buffalo.edu

[d] Dr. N. Vanthuyne, Prof. C. Roussel Aix Marseille Université, Centrale Marseille, CNRS, iSm2 UMR 7313, 13397, Marseille (France)

Supporting information for this article is given via a link at the end of the document.((Please delete this text if not appropriate)) to improve and tune their chiroptical properties. In this regard, the most appealing general approach developed up to now involves the modifications of the 'screw-shaped' ortho-fused polycyclic $\pi$ framework, since the unique chiroptical properties of helicenes are inherently linked to this helicoidal conjugated skeleton. The strategy includes for example the modification of the helical pitch, the increase in the number of fused aromatic rings, or the incorporation of heteroatoms or transition metals within the $\pi$ skeleton. ${ }^{[1,6]}$

In 2012, we have described a new strategy of the molecular engineering of helicenes based on the grafting of lateral substituents on the $\pi$-helical platform via a vinyl bridge. ${ }^{[4 a, b]}$ The approach uses 2-ethynyl-[6]helicene precursors 1a,b (Scheme 1) which are easily accessible in an enantiomerically pure form on a gram-scale, and which can be easily substituted by introduction of lateral organometallic fragments via well-established hydrometallation. ${ }^{[7]}$ In the present account, the approach and its outcome are described in detail for ruthenium-grafted vinylhelicenes ${ }^{[4 a]}$ focusing on their chiroptical properties and redox chiroptical switching activity. Mono- and bis-metal-vinylhelicene complexes $\mathbf{2 a , b}$ were readily prepared from pristine helicenes 1a,b (Scheme 1) and correspond to carbon-rich $d^{6}$ metal systems with a helical topology. ${ }^{[4 a, b]}$ Remarkably, introducing remote heavy metal centers results in a dramatic modification of the chiroptical properties of helical $\pi$-platform $\mathbf{1 a}, \mathbf{b}$. The optical rotation parameters (OR), electronic circular dichroism (ECD) and vibrational circular dichroism (VCD) spectra of both ligands $\mathbf{1 a , b}$ and organometallic ruthenium-vinyl grafted helicenes $\mathbf{2} \mathbf{a}, \mathbf{b}$ were studied experimentally and computationally. Furthermore, due to 
the redox properties of the lateral $\mathrm{Ru}$ "l metal center(s), these organometallic helicenes are demonstrated to be electrocommutable systems. ${ }^{[7]}$ The radical mono-cationic and biscationic species of $\mathbf{2} \mathbf{a}, \mathbf{b}$ were thus obtained upon one or two electron oxidations and observed by means of IR, UV-vis/NIR and ECD spectroscopy. These redox processes were found to significantly impact the chiroptical properties, affording efficient helicene-based redox chiroptical switches. ${ }^{[\mathrm{h}, 4 \mathrm{a}]}$ The results are rationalized with the help of quantum-chemical analysis.

\section{Results and Discussion}

\section{Synthesis and structure of mono-Ru-vinylhelicene $\mathbf{2 a}$}

The $\mathrm{Ru}$ " metal ion was selected in this strategy because its complexes are electro-active at low potential ${ }^{[7 b-i, 8]}$ and may allow for the synthesis of original redox-triggered NLO-active, ${ }^{[9 a]}$ luminescent ${ }^{[9 b, c]}$ and electrochromic ${ }^{[9 \mathrm{~d}]}$ switches. As reported in 2012, ${ }^{[4 a]}$ 2-ethynyl-[6]helicene 1a (Scheme 1) was readily obtained on gram scale using classic photocyclization reactions ${ }^{[1]}$ from appropriate olefins bearing para-ethynyl-subtituents and was resolved by HPLC separation over a chiral stationary phase. Reaction of 1a with one equivalent of $\mathrm{RuH}(\mathrm{CO}) \mathrm{Cl}\left(\mathrm{P}^{i} \mathrm{Pr}_{3}\right)_{2}$ afforded the organometallic derivative $\mathbf{2 a}$, which was isolated in high yields ( > 90\%) as an air-stable dark-red solid (Scheme 1). Its NMR data fully support the proposed structure, especially the presence of trans-vinyl metal-substituted moiety. For example, both ${ }^{1} \mathrm{H}$ and ${ }^{13} \mathrm{C}$ NMR spectra display the typical fingerprints for this fragment ( ${ }^{1} \mathrm{H}$ NMR: doublet at $\delta=8.4$ and $5.4 \mathrm{ppm}, \mathrm{J}_{\mathrm{HH}}=13.4 \mathrm{~Hz} ;{ }^{13} \mathrm{C}$ NMR: two triplets at $\delta=134.4 \mathrm{ppm},{ }^{3} \mathrm{JP}_{\mathrm{P}-\mathrm{C}}=3.0 \mathrm{~Hz}$ and $\delta=150.6$ $\mathrm{ppm},{ }^{2} \mathrm{~J}_{\mathrm{P}-\mathrm{C}}=10.7 \mathrm{~Hz}$ ). Due to the presence of the helicene ligand, the two $\mathrm{P}^{i} \mathrm{Pr}_{3}$ ligands are magnetically non-equivalent $\left({ }^{31} \mathrm{P} \mathrm{NMR}\right.$ $\delta=37.4$ and $\left.39.4 \mathrm{ppm},{ }^{2} \mathrm{JPP}=275.0 \mathrm{~Hz}\right) .^{[4 \mathrm{a}]}$

The X-ray structure of $\mathrm{Ru}$ "-capped helicene 2a (Figure 1) was described earlier by us and revealed the coplanarity between the ruthenium, the vinyl moiety and the adjacent fragment of the helical core, ensuring an efficient electronic interaction between the helicene ligand and the Ru center via the vinyl bridge, ${ }^{[4 a]}$ as illustrated below by UV-vis and circular dichroism spectroscopy.

\section{UV-vis and ECD spectroscopic studies on mono-Ru- vinylhelicene $\mathbf{2 a}$}

The UV-vis and ECD spectra of the complex $\mathbf{2 a}$ compared to the pristine helicene 1a are displayed in Figures 2 and 3 , respectively (see also Supporting Information, SI). The MO-pairs assignment of selected intense excitations is provided in Table 1. The corresponding molecular orbitals involved in the transitions are depicted in Figure 4.

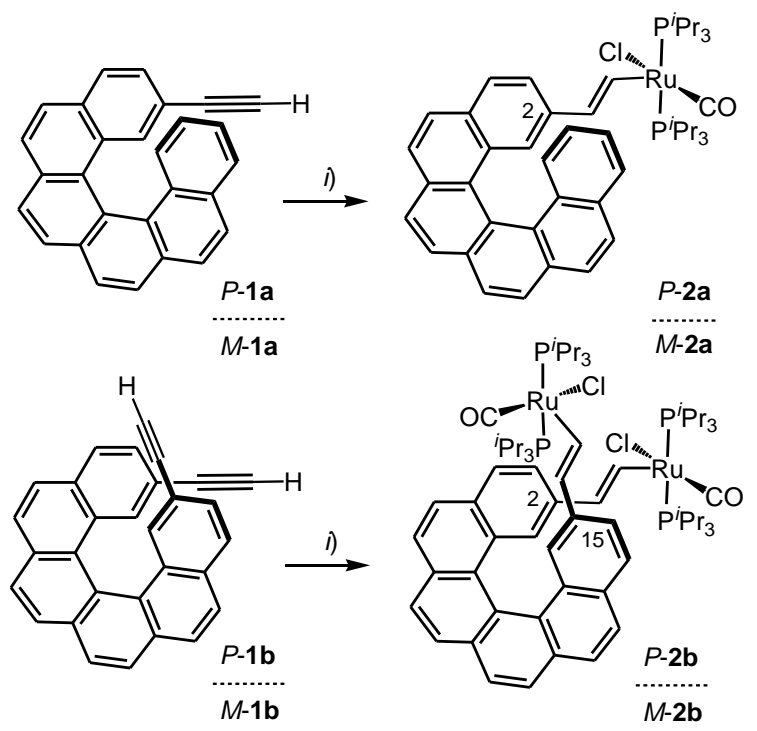

Scheme 1. Synthesis of enantiopure $P$ - and $M$ - ruthenium-grafted vinylhelicene derivatives 2a,b. I) $\mathrm{RuH}(\mathrm{CO}) \mathrm{Cl}\left(\mathrm{P}^{i} \mathrm{Pr}_{3}\right)_{2}, \mathrm{CH}_{2} \mathrm{Cl}_{2}$ or toluene, r.t., Ar.

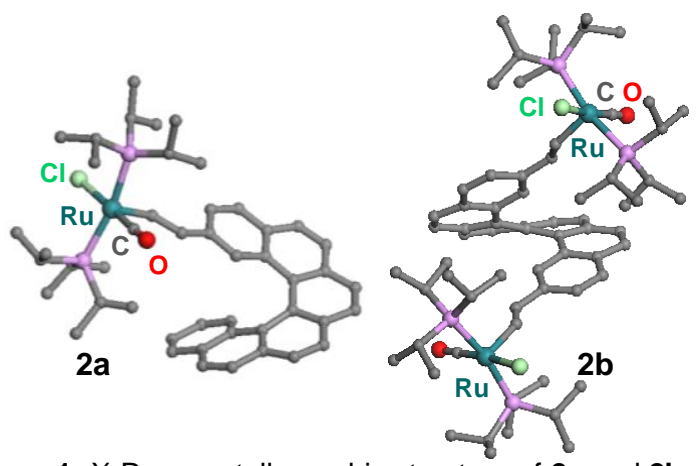

Figure 1. X-Ray crystallographic structure of $\mathbf{2 a}$ and $\mathbf{2 b}$. Only $P$ enantiomers shown; $\mathrm{H}$ atoms omitted for clarity. ${ }^{[4 a]}$

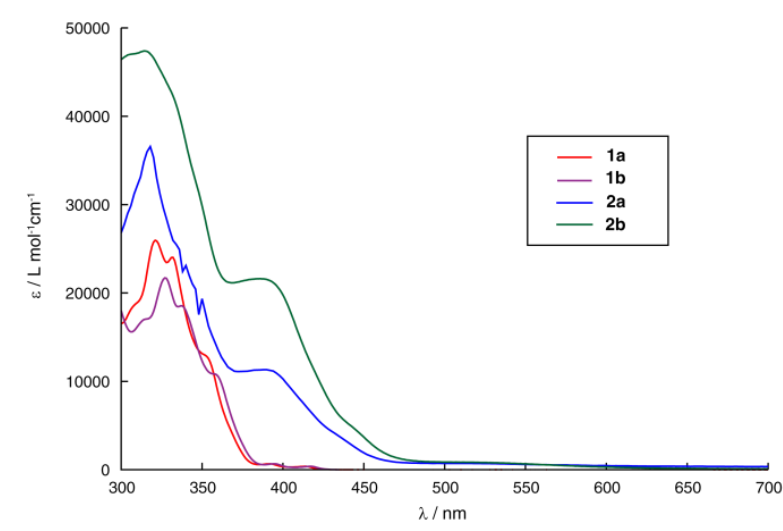

Figure 2. UV-vis spectra in $\mathrm{CH}_{2} \mathrm{Cl}_{2}$ at $293 \mathrm{~K}$ of mono- and bisethynyl-helicenes $\mathbf{1} \mathbf{a}, \mathbf{b}$ and of the corresponding mono- and bisruthenium-grafted vinylhelicene derivatives $\mathbf{2 a} \mathbf{a}, \mathbf{b}$.

The electronic $\pi$-interaction between ruthenium and vinyl[6]helicene in $\mathbf{2 a}$ was indeed confirmed by UV-vis spectroscopy (Figure 2 and Figure S5, SI) which demonstrated ( $I$ ) typical helicene-centered $\pi-\pi^{*}$ absorption bands around $320 \mathrm{~nm}$ of enhanced intensity comparing to $1 \mathbf{a}$, along with (ii) wide lowenergy bands between 380 and $600 \mathrm{~nm}$ that do not exist in 1a. $\mathrm{BHLYP} / \mathrm{SV}(\mathrm{P})$ calculations at $\mathrm{BP} / \mathrm{SV}(\mathrm{P})$-optimized structures show that the HOMO spans over the metal and the vinylhelicene 
moiety (Figure 4a), and dominant contributions to the lowerenergy excitations involve both metal and helicene orbitals.

The 1a enantiomers display intense experimental ECD spectra ( $P-1 \mathrm{a}: 270 \mathrm{~nm}, \Delta \varepsilon=-111 \mathrm{M}^{-1} \mathrm{~cm}^{-1} ; 332 \mathrm{~nm}, \Delta \varepsilon=+188 \mathrm{M}^{-}$ ${ }^{1} \mathrm{~cm}^{-1}$ in $\mathrm{CH}_{2} \mathrm{Cl}_{2}$, Figure $3 a$ top) that are typical for organic carbo[6]helicenes. ${ }^{[1,4 a]}$ The comparison of chiroptical properties of the ethynyl-capped [6]helicene with the parent carbo[6]helicene indicates that introducing one ethynyl moiety on a [6]-helicene core has indeed a slight effect on its chiroptical properties (compare with Table 2). ${ }^{[10 a, b]}$ The experimental ECD spectrum of $P$-2a (Figure 3a top) displays $I$ ) an intense negative band at 250 $\mathrm{nm}$, ii) a strong positive one at $335 \mathrm{~nm}$ that appears to originate from the helicene's $\pi-\pi^{*}$ excitation $n^{\circ} 6$ calculated at $325 \mathrm{~nm}$ and displaying the strongest calculated rotatory strength, and iii) new low-energy positive bands of moderate magnitude (380-460 nm) which are not present in the spectrum of $1 \mathbf{a}$ and correspond to excitations $n^{\circ} 5, n^{\circ} 3$ and $n^{\circ} 2$ (Figure 3a bottom, Table 1, Figure 4a). Excitations $\mathrm{n}^{\circ} 5$ and $\mathrm{n}^{\circ} 3$ (mainly HOMO-LUMO+1 and HOMO-LUMO, respectively) manifest pronounced $\pi-\pi^{*}$ character within the helicene moiety with some charge-transfer (CT) signature, but they are also enhanced by metal-orbital involvement. The $\mathbf{2 a}$ excitation $n^{\circ} \mathbf{2}$ dominantly involves a pair of MOs centered on the metal ion (HOMO-6, formally a $t_{2 \mathrm{~g}}$ metal $d$ orbital with carbonyl $\pi^{*}$-backbonding character, and LUMO+2, also a metal-centered orbital) with negligible contributions from the helicene $\pi$-electron system. Similar low-energy ECD bands with significant contributions from metal-centered orbitals and of relatively weak intensity of the transition were found to be present in other metal-based helicene derivatives. ${ }^{[6 a, 10 c, d]}$ According to the analysis, it is justified to consider the $\mathrm{Ru}$ " center responsible for the low-energy (long-wavelength) tail of the first positive CD band leading in consequence to an increase in the optical rotation of the ruthenium-vinylhelicene derivative compared to the organic precursor (vide infra). The dominant factor responsible for the large optical rotation of the ruthenium complex is the increase in the rotatory strengths of the low-energy $\pi-\pi^{*}$ transitions localized in the helicene moiety due to metal orbital involvement.

Optical rotation (OR) of mono-Ru-vinylhelicene $2 \mathrm{a}$
The enantiopure Ru-vinyl[6]helicene complex 2a displays a similar specific rotation to 1 a in $\mathrm{CH}_{2} \mathrm{Cl}_{2}$ (Table 2). However, to be able to objectively assess the influence of the metal center on the OR in both systems, one must compare the molar rotation (MR) parameters that take into account the molecular weights of compounds. Interestingly, the MR value of $2 a\left(\phi_{\phi}\right]^{3}= \pm 23770^{\circ}$ $\left.\mathrm{cm}^{2} / \mathrm{dmol}\right)$ is twice that of $1 \mathrm{a}\left([\phi]_{D}^{23}= \pm 11030^{\circ} \mathrm{cm}^{2} / \mathrm{dmol}\right)$ confirming a pronounced effect of the metal ion $\mathrm{Ru}^{\text {II }}$ on helical $\pi$ backbone.

A comparison of the experimental with calculated ORs using different computational models is presented in Table 2. Recent studies on chiroptical properties of pristine and substituted helicene have emphasized the role of dispersive (van der Waals, $v d W$ ) forces in the geometry optimizations to ensure an accurate description of the chiroptical properties. ${ }^{[10 b, 13]}$ Likewise, inclusion of solvent effects can potentially be important. Overall (Table 2), inclusion of vdW interactions appears to be indispensable in order to reach even fair agreement between calculated and experimental MRs for the alkynyl-substituted [6]helicene 1a using hybrid functionals. In the case of the metal complex 2a this leads however to some deterioration of the computed MRs relative to experiment. Overlays of structures optimized without and with vdW corrections with the X-ray crystal structure (Figure 5) show larger deviations for the latter; as for other helicene-based systems that we studied in the past there is no clear improvement for the structures of $\mathbf{1 a}$ and $\mathbf{2} \mathbf{a}$ from the vdW corrections. ${ }^{[13 a]}$ The agreement of calculated and experimental MRs may be further improved by employing long-range corrected (LC) hybrid functionals. ${ }^{[10 b, 13 a, c]}$

It is worth emphasizing, however, that although the theoretical MRs in some cases exhibit sizable differences from the experimental values, the trends are maintained: the bonding of the alkynyl-substituted helicene to ruthenium leads to an increased magnitude of the MR which is consistent with the increase in the intensity of the low-energy tail of the ECD spectrum of $\mathbf{2 a}$ vs. 1a due to metal orbital involvement (vide supra). 
a)

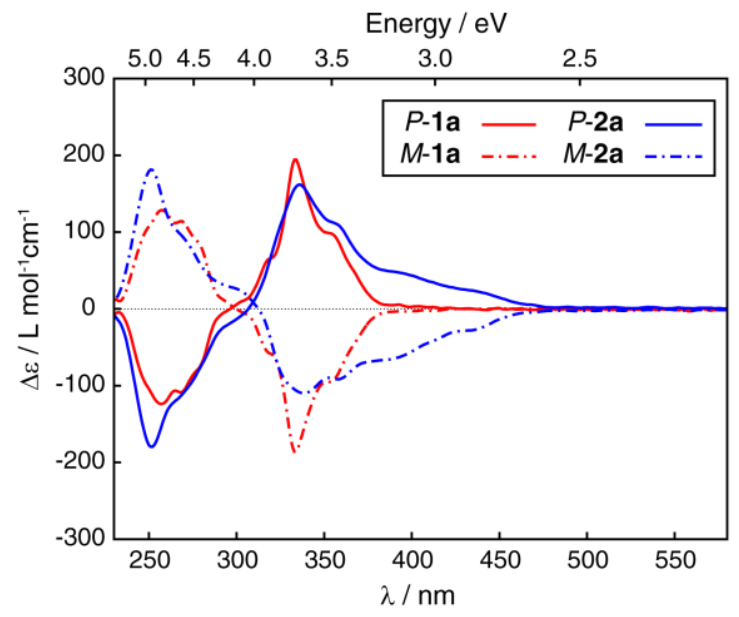

b)

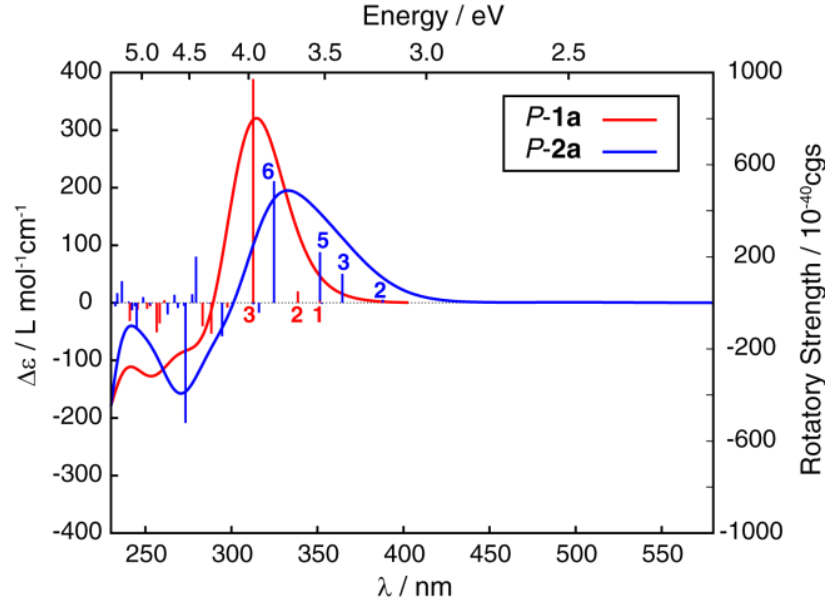



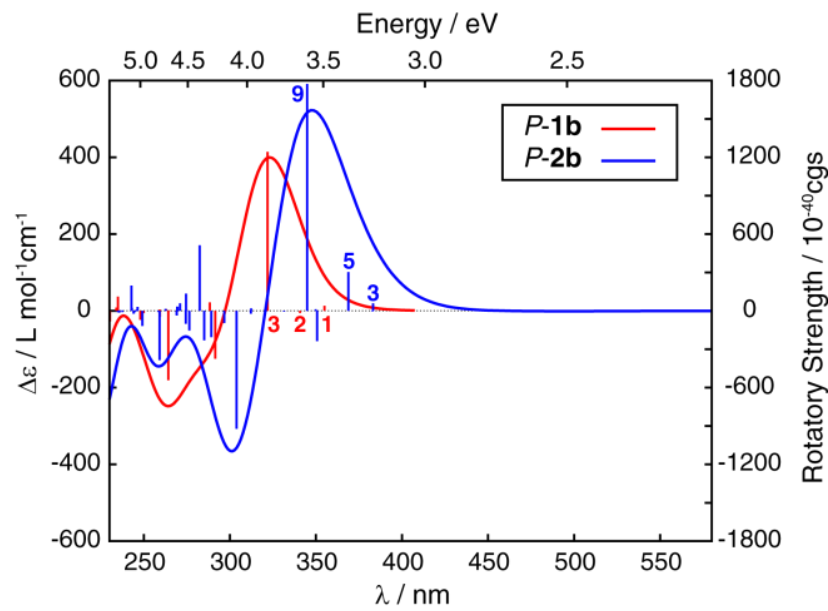

Figure 3. ECD spectra in $\mathrm{CH}_{2} \mathrm{Cl}_{2}$ at $293 \mathrm{~K}$ of a) enantiopure mono-alkynyl precursors $P-(+)$ - and $M-(-)-1$ a and the corresponding mono-ruthenium-grafted vinyl-helicene derivatives $P-(+)$ - and $M-(-)-2 \mathrm{a}$ and of $\mathrm{b})$ enantiopure bis-alkynyl precursors $P-(+)$ - and $M-(-)$ -

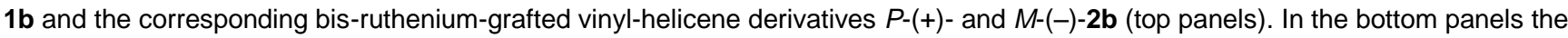
corresponding simulated BHLYP/SV(P) TDDFT ECD spectra are shown. No spectral shift has been applied. Numbered excitations correspond to those analyzed in detail in Table 1 and SI.

Table 1. Selected excitations along with occupied (occ) - unoccupied (unocc) MO-pair contributions (greater than $10 \%$ ) of $P-2 a$ and $P$ 2b.

\begin{tabular}{|c|c|c|c|c|c|c|}
\hline Excitation & $E / \mathrm{eV}$ & $f$ & $R / 10^{-40} \mathrm{cgs}$ & occ no. & unocc no. & $\%$ \\
\hline \multicolumn{7}{|c|}{$2 a$} \\
\hline \#2 & 3.20 & 0.0283 & 13.41 & 200 & 209 & 70.6 \\
\hline \multirow[t]{3}{*}{ \#3 } & 3.40 & 0.0546 & 125.60 & 206 & 207 & 64.6 \\
\hline & & & & 205 & 208 & 14.8 \\
\hline & & & & 204 & 207 & 10.9 \\
\hline \multirow[t]{2}{*}{ \#5 } & 3.53 & 0.1814 & 220.03 & 206 & 208 & 58.1 \\
\hline & & & & 205 & 207 & 18.7 \\
\hline \multirow[t]{2}{*}{$\# 6$} & 3.82 & 0.2352 & 528.55 & 205 & 207 & 39.4 \\
\hline & & & & 205 & 208 & 34.0 \\
\hline \multicolumn{7}{|c|}{$2 b$} \\
\hline \multirow[t]{2}{*}{$\# 3$} & 3.24 & 0.0574 & 58.86 & 318 & 330 & 37.4 \\
\hline & & & & 319 & 329 & 36.9 \\
\hline \#5 & 3.36 & 0.0611 & 303.83 & 326 & 327 & 69.9 \\
\hline
\end{tabular}




\begin{tabular}{|l|l|l|l|l|l|l|}
\hline & & & & 324 & 328 & 13.0 \\
\hline$\# 9$ & 3.60 & 0.4183 & 1773.43 & 325 & 328 & 58.9 \\
\hline & & & & 324 & 328 & 15.9 \\
\hline & & & & 326 & 331 & 11.2 \\
\hline
\end{tabular}

a)


b)
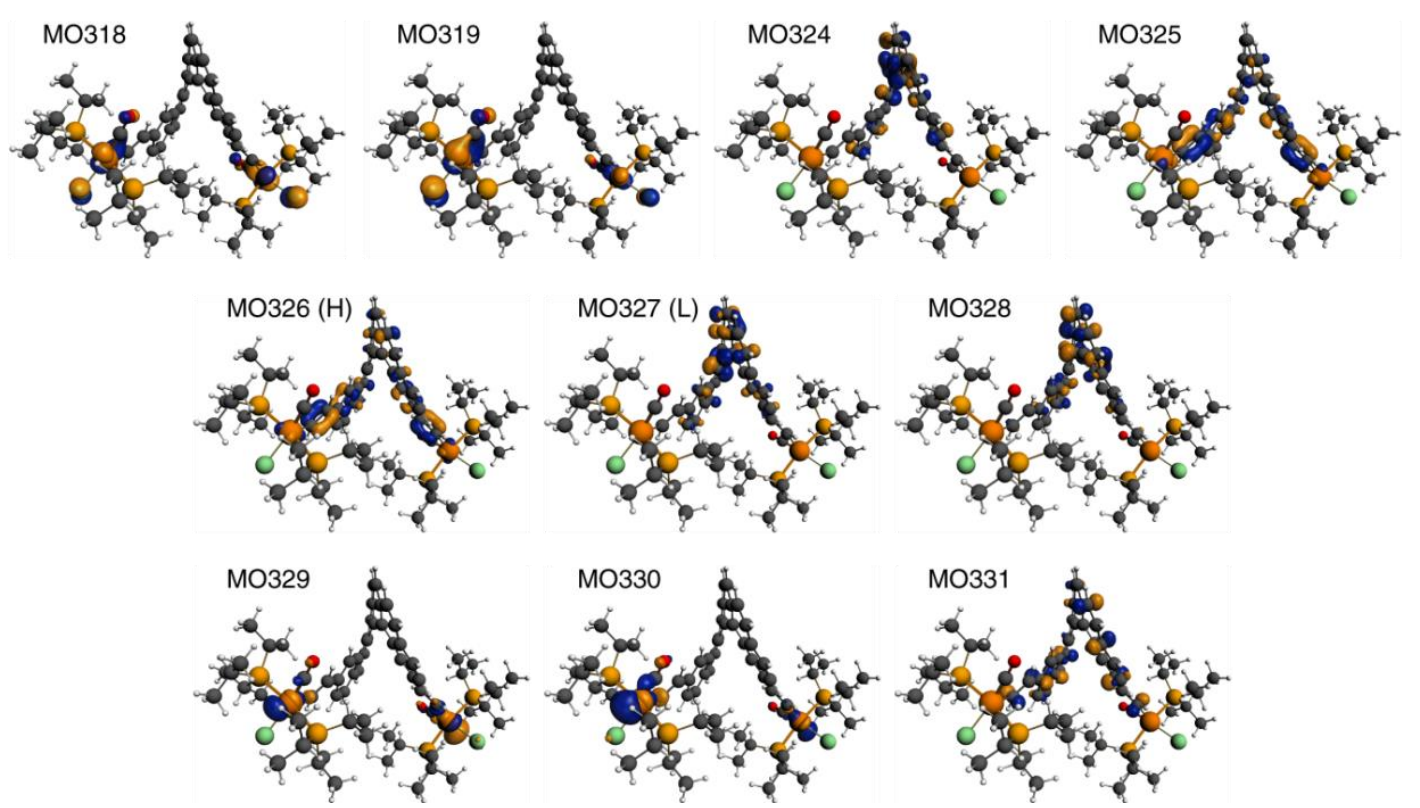

Figure 4. Isosurfaces ( $0.05 \mathrm{au})$ of MOs involved in selected transitions of $\mathbf{2 a}$ (panel a) and $\mathbf{2} \mathbf{b}$ (panel b). 'H' = HOMO, 'L' = LUMO. 

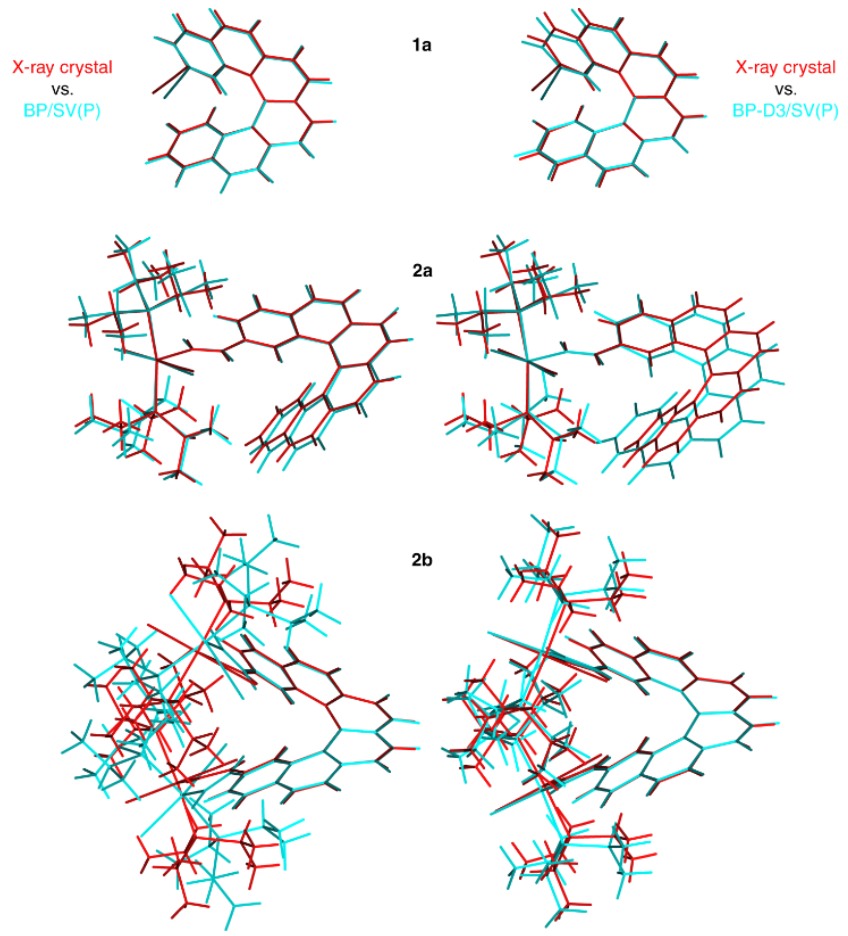

Figure 5. Overlays of calculated BP/SV(P), BP-D3/SV(P), and experimental $\mathrm{X}$-ray crystal structures of $\mathbf{1 a}, \mathbf{2 a}$, and $\mathbf{2} \mathbf{b}$.

\section{Synthesis and structure of bis-Ru-vinylhelicene 2b}

The results for the mono-Ru-vinylhelicene complex 2a revea that grafting one remote, but conjugated, Ru"-fragment onto a helicene platform provides an unexpectedly simple way of considerable enhancement its chiroptical properties. The question then arose whether this approach can be applied to two Ru"fragments. Therefore, the same general molecular engineering was applied to the previously known 2,15bis(ethynyl)[6]helicene ${ }^{[14,4 a]} \mathbf{1 b}$ (Scheme 1), which was obtained in an enantiomerically pure form $(e e>98 \%)$ following the general procedure used for $\mathbf{1 a} .^{[4 a]}$ The synthesis of bi-metallic species $\mathbf{2 b}$ was then achieved by reacting 2 equivalents of $\mathrm{RuH}(\mathrm{CO}) \mathrm{Cl}\left(\mathrm{P}^{\prime} \mathrm{Pr}_{3}\right)_{2}$ with 1b (Scheme 1). Organometallic derivative 2b was isolated in a high yield (80\%) as an air-stable red solid. The simplicity of their ${ }^{1} \mathrm{H},{ }^{13} \mathrm{C}$ and ${ }^{31} \mathrm{P}$ NMR spectra are consistent with a $\mathrm{C}_{2}$-symmetry (see experimental part and ref. [4a]). The NMR spectroscopic signatures for the vinyl-metal moieties are similar to those of the corresponding mono-metallic species and bi-metallic species, ${ }^{\left[{ }^{9 e}\right]}$ indicating a highly stereoselective functionalization. The X-ray crystal structure of the complex $\mathbf{2 b}$ is depicted in Figure 1. As previously discussed, it displays the same characteristic features as the $2 \mathbf{a}$ system. ${ }^{[4 a]}$

\section{UV-vis and ECD spectroscopic studies on bis-Ru- vinylhelicene $\mathbf{2 b}$}

The UV-vis spectrum of $\mathbf{2} \mathbf{b}$ is overall similar to that of monometallic species 2a but much more intense (Figure 2 and Figure S5, SI). Namely, as compared to the parent helicene 1b, the UVvis bands for $\mathbf{2 b}$ are much stronger and additional low-energy absorption bands $(380-600 \mathrm{~nm})$ are present as a result of incorporation of two Ru" centers within the helicene $\pi$-system. As far as ECD is concerned, the corresponding spectral envelopes in $\mathbf{2 b}$ are different from those of both its organic precursor $\mathbf{1 b}$ and its mono-metallic analog 2a (Figure $3 \mathrm{~b}$ ). The positive ECD-active bands of $P$-2b displaying the highest $\Delta \varepsilon$ values were found between 380-430 nm (Figure 3b top). They correspond to $\pi-\pi^{\star}$ type excitations localized in the helicene $\pi$-system with visible participation of the ruthenium $d$ orbitals. For example, excitation $\mathrm{n}^{\circ} 9$ calculated at $345 \mathrm{~nm}$ involves predominantly the HOMO-1 LUMO +1 pair of orbitals (see Figure $3 b$ bottom, Table 1, and Figure 4b). Additionally, a separate positive band with moderate intensity at low-energy $(450 \mathrm{~nm})$ can be observed for $P$-2b, which mainly originates from excitations $n^{\circ} 5$ and $n^{\circ} 3$. Excitation $n^{\circ} 5$ (369 nm) is predominantly assigned as a HOMO-LUMO transition, i.e. a $\pi-\pi^{*}$ transition within the helicene moiety enhanced by the metal orbitals. Excitation $n^{\circ} 3(383 \mathrm{~nm})$ involves two main contributions from MOs centered on the metal ions only (see Table 1 and Figure 4b). We emphasise the strong resemblance in the spectral features, MO characteristics, and spectral assignments of dominant excitations, for the mono- and bis-ruthenium-grafted vinylhelicenes. In particular, the low-energy tail of the $\mathbf{2} \mathbf{b}$ ECD spectrum appears to have essentially the same origin as in $\mathbf{2 a}$, but it has higher intensity, which points to an enhancement mechanism via electronic coupling of the two metal centers with the terminal rings of helicenic ligand. ${ }^{[15]}$

Table 2. Experimental specific and molar rotations along with calculated molar rotations of enantiopure mono- and bissubstituted ethynyl[6]helicenes $P-\mathbf{1 a}$ and $P-\mathbf{1 b}$, of the corresponding mono- and bis-ruthenium-grafted vinylhelicene derivatives $P-\mathbf{2} \mathbf{a}$ and $P-\mathbf{2} \mathbf{b}$, and of the pristine [6] helicene.

\begin{tabular}{|c|c|c|c|c|c|}
\hline & [6]helicene & $1 a$ & $1 \mathrm{~b}$ & $2 a$ & $2 b$ \\
\hline \multicolumn{6}{|c|}{ Experimental $[\alpha]_{D}^{23},[\phi]_{D}^{23}$} \\
\hline$[\alpha]_{D}^{23}[\mathrm{a}, \mathrm{b}, \mathrm{b}]$ & $3640^{[11]}$ & 3133 & 5180 & 2850 & 2909 \\
\hline$[\phi]_{D}^{23}[\mathrm{a}, \mathrm{c}]$ & $11950^{[11]}$ & 11030 & 20000 & 23770 & 39150 \\
\hline \multicolumn{6}{|c|}{ Calculated BHLYP/SV(P)//geometry $[\phi]_{D}{ }^{[\mathrm{c}, \mathrm{d}]}$} \\
\hline BP & 12435 & 17002 & 22230 & 20583 & 44925 \\
\hline BP solvent & - & 16122 & 21163 & 20548 & 42135 \\
\hline BP-D3 & - & 15884 & 20617 & 15150 & 36892 \\
\hline $\begin{array}{l}\text { BP-D3 } \\
\text { solvent }\end{array}$ & - & 15041 & 19945 & 15819 & 37995 \\
\hline X-ray crystal & - & 12662 & - & 14871 & 25811 \\
\hline
\end{tabular}

[a] Measured in $\mathrm{CH}_{2} \mathrm{Cl}_{2}$. Concentrations of $1-5 \cdot 10^{-5} \mathrm{M}$. Errors of $5-10 \%$. [b] In $\operatorname{deg} /\left(\mathrm{dm} \mathrm{g} / \mathrm{cm}^{3}\right)$. [c] In deg $\mathrm{cm}^{2} \mathrm{dmol}^{-1}$. [d] BHLYP/SV(P) calculations for geometries optimized with BP/SV(P) ('BP'), BP/SV(P) with continuum solvent model for dichloromethane ('BP solvent'), BP-

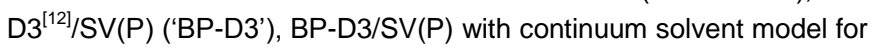
dichloromethane ('BP-D3 solvent'), and for X-ray crystal structures.

\section{Molar rotation of bis-Ru-vinylhelicene $\mathbf{2 b}$}

Like for complex $\mathbf{2 a}$, the low-energy ECD tail in the bis-Ruvinylhelicene $\mathbf{2 b}$ may cause an enhancement of the MR as compared to the pristine helicene $\mathbf{1 b}$. Indeed, the experimental MR for enantiopure $\mathbf{2 b}\left([\phi]_{D}^{23}= \pm 39150^{\circ} \mathrm{cm}^{2} / \mathrm{dmol}\right)$ is twice that of $\mathbf{1 b}\left([\phi]_{D}^{3}= \pm 20000^{\circ} \mathrm{cm}^{2} / \mathrm{dmol}\right)$ and four times that of $\mathbf{1 a}$ (Table 2$)$ Note that also the MRs of $\mathbf{1 b}$ enantiomers have large magnitudes and that ECD spectra of $\mathbf{1} \mathbf{b}$ display a similar shape to those of $\mathbf{1 a}$ but with higher intensity (Figure 3 top). ${ }^{[16]}$ TDDFT calculations with BHLYP/SV(P) well reproduce the experimental MRs for both $\mathbf{1 b}$ and $\mathbf{2 b}$ (Table 2), thereby nicely illustrating the effect of the extension of the $\pi$-chromophore when two ethynyl moieties are 
grafted at the 2,15 positions and the effect of introducing two metal centers on the helicene $\pi$-platform. The calculated BHLYP MRs seem to be relatively insensitive to the level of geometry optimization (DFT vs. DFT-D3) and solvent effects. With all computational models considered, the calculated MRs range between 19000 and $23000^{\circ} \mathrm{cm}^{2} / \mathrm{dmol}$ and between 36000 and $45000^{\circ} \mathrm{cm}^{2} / \mathrm{dmol}$ for $\mathbf{1 b}$ and $\mathbf{2 b}$, respectively. BP-D3 geometry optimizations give slightly better agreement with experiment than using structures optimized without vdW corrections, and the experimental MRs are almost perfectly reproduced upon inclusion of solvent effects in the calculation ('BP-D3 solvent' entry in Table 2). Inclusion of dispersion corrections during geometry optimization of $\mathbf{2} \mathbf{b}$ affects primarily the relative orientation of the Ru-vinyl moieties, and unlike for $\mathbf{1 a}$ and $\mathbf{2 a}$ provides better overlay with the X-ray crystal structure (Figure 5).

To conclude, these results illustrate the power and simplicity of organometallic chemistry to produce new chiral molecular architectures using stereoselective hydrometalation of readily available organic helicene platforms. This is experimentally confirmed and theoretically rationalized here by the fact that introducing remote $\mathrm{Ru}$ "-metal center(s) results in a profound modification of their ECD spectra and MRs, due to an electronic coupling between the $\mathrm{Ru}$ "I ion(s) and the helicoidal $\pi$-system via the vinyl moiety.

\section{Analysis of VCD spectra for alkynyl-substituted helicenes $1 \mathrm{a}, \mathrm{b}$ and metal derivatives $2 \mathrm{a}, \mathrm{b}$}

Vibrational Circular Dichroism (VCD) spectroscopy ${ }^{[17 a-c]}$ of organic helicenes has been used by different groups in order to examine their general characteristic VCD fingerprints, ${ }^{[18 a-d]}$ to determine their absolute configuration, ${ }^{[18 \mathrm{e}-\mathrm{h}]}$ or to evaluate various theoretical models. ${ }^{[18 i, j]}$ However, to the best of our knowledge, no VCD spectra of metal-based helicene derivatives have been reported to date. ${ }^{[17 d]}$ The experimental IR and VCD spectra of enantiopure $P-(+)$ and $M-(-)$ organic helicenes $\mathbf{1} \mathbf{a}, \mathbf{b}$ and of the corresponding enantiopure $P-(+)$ and $M-(-)$ Ru-vinyl complexes 2a,b are depicted in Figure 6. The simulated B3LYP-D3/SV(P) spectra are compared with experiment in Figure 7 (see also $\mathrm{SI}$ ). The frequencies of the selected (numbered) VCD active vibrations along with dipole and rotatory strength values are collected in Tables 3 and 4 for $\mathbf{1 a}$ and $\mathbf{2 a}$, respectively. Atomic displacements of particular vibrations are presented in Figures 8 and 9 . The corresponding data for $\mathbf{1 b}$ and $\mathbf{2 b}$ and a detailed assignment of selected VCD active modes are given in the SI.

$P-(+)$ enantiomers of $\mathbf{1 a}$ and $\mathbf{1} \mathbf{b}$ display very clear experimental VCD signatures in three different regions: $i$ ) a set of negative intensities between $1200 \mathrm{~cm}^{-1}$ and $1350 \mathrm{~cm}^{-1}$, ii) a strong negative-positive bisignate signal at $1500-1520 \mathrm{~cm}^{-1}$ and iii) a negative band at $1600 \mathrm{~cm}^{-1}$; all very well reproduced by the calculations (Figures 6 and 7). These three regions are typical for all organic helicenes and correspond mainly to $\mathrm{CCH}$ bending modes in the region i) and aromatic $\mathrm{C}=\mathrm{C}$ stretches in regions ii) and iii). All these modes are coupled vibrations involving multiple groups, as revealed by quantum-chemical analysis (Table 3 and Figure 8; see $\mathrm{SI}$ for more details). For example, the bisignate VCD around $1500 \mathrm{~cm}^{-1}$ involves atomic displacements along the entire helicene moiety, corresponding to a type of breathing modes of the helicene moiety. Note that although inclusion of dispersion corrections in the geometry optimizations with DFT-D3 visibly affects the helicene structures (Figure 5), overall qualitative and quantitative agreement is observed for both B3LYP and B3LYP-D3 calculated IR and VCD spectra for 1a and 1b (Figure S2, SI).
Organometallic ruthenium species $\mathbf{2 a} \mathbf{a} \mathbf{b}$ show generally similar IR and VCD active bands as their parent helicenes $\mathbf{1 a}, \mathbf{b}$ but with some differences that stem from $i$ ) the presence of the vinyl moieties and the additional tri-isopropyl phosphine ligands and $i$ ) the additional degrees of freedom furnished by these units (Figure 6). In the $\mathrm{CCH}$ bending region, between 1200 and 1350 $\mathrm{cm}^{-1}$, the VCD bands now have different signs. The clear strong bisignate signature between $1490-1510 \mathrm{~cm}^{-1}$ corresponding to the breathing mode of the helicene (mainly coupled aromatic $\mathrm{C}=\mathrm{C}$ stretches) is still present in the $\mathbf{2} \mathbf{a}$ and $\mathbf{2} \mathbf{b}$ complexes, while several new additional bands appear between 1520 and $1580 \mathrm{~cm}$ 1 that are assigned to vinyl $\mathrm{C}=\mathrm{C}$ stretches coupled to the vibrational modes of the helix. Finally, a set of small IR and VCD active bands around $1600 \mathrm{~cm}^{-1}$ are present in mono- and bisruthenium complexes. As for the absorption coefficients, Ruvinylhelicenes $\mathbf{2 a}$, $\mathbf{b}$ show experimental IR spectra that are much more intense than their corresponding organic helicenes (4 times for mono and 10 times for bis-Ru derivatives), due to stronger electric dipolar transition moments. This effect is often encountered in organometallic species that introduce more charge density in the structure. ${ }^{[19]}$ Electronic low-lying levels introduced by some metallic ions can also induce VCD enhancement. ${ }^{[20]}$ Similarly, the VCD spectra of $\mathbf{2 a , b}$ are slightly more intense than for the mono- and 10 times stronger than for the bis-alkynyl substituted helicenes $\mathbf{1 a}, \mathbf{b}$. However, the dissymmetry factors of typical bands are of similar magnitude in the ruthenium-based helicenes as compared to pristine helicenes (for example, $\mathrm{g} \sim 1.0 \cdot 10^{-4}$ for $\mathbf{2 a}$ and $5.5 \cdot 10^{-4}$ for $\mathbf{2 b}$ at 1503 and 

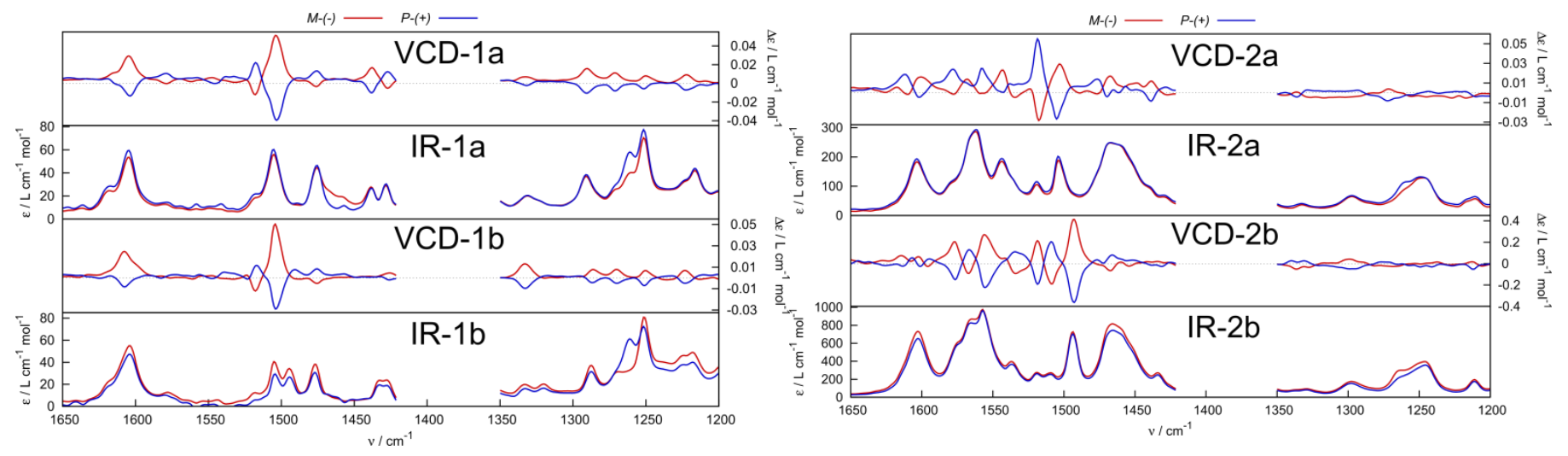

Figure 6. Experimental IR and VCD spectra for $P-(+)$ and $M-(-)$ mono- and bis-alkynylhelicenes (1a,b) and $P$-(+) and $M-(-)$ mono- and bis-ruthenium-vinylhelicenes (2a,b). VCD spectra measured in $\mathrm{CD}_{2} \mathrm{Cl}_{2}$ at $293 \mathrm{~K}$ (concentrations $15 \mathrm{mg}$ in $0.7 \mathrm{~mL} ; 0.5 \mathrm{~mm}$ pathlength; 3000 scans).

a)

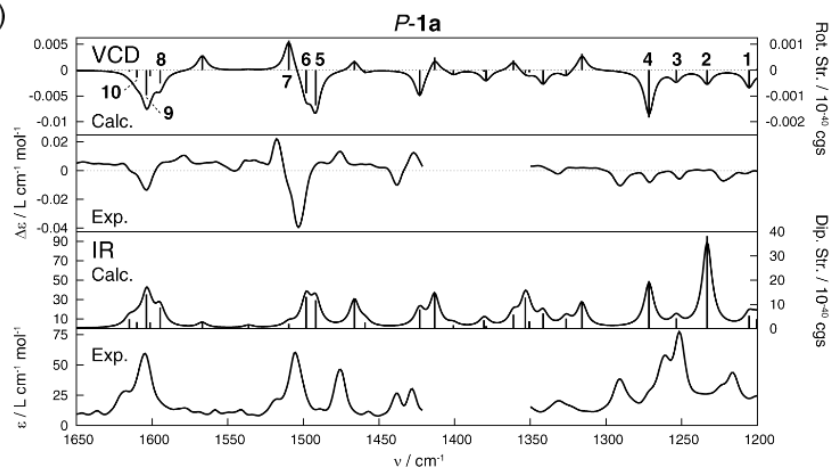

b)

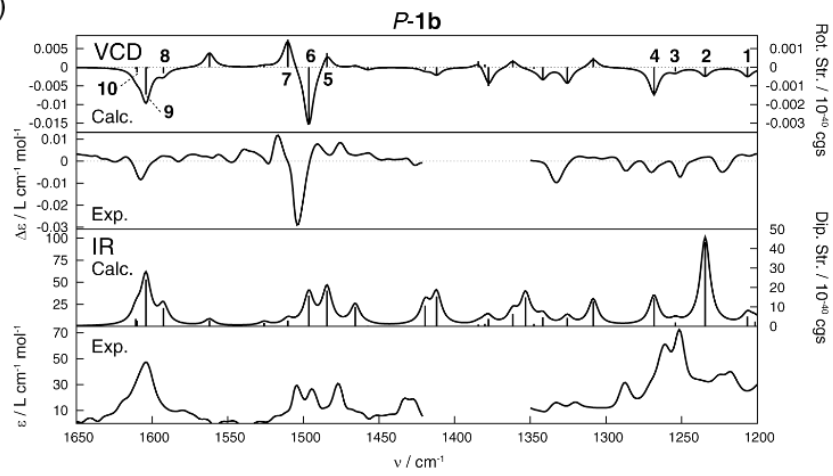

c)

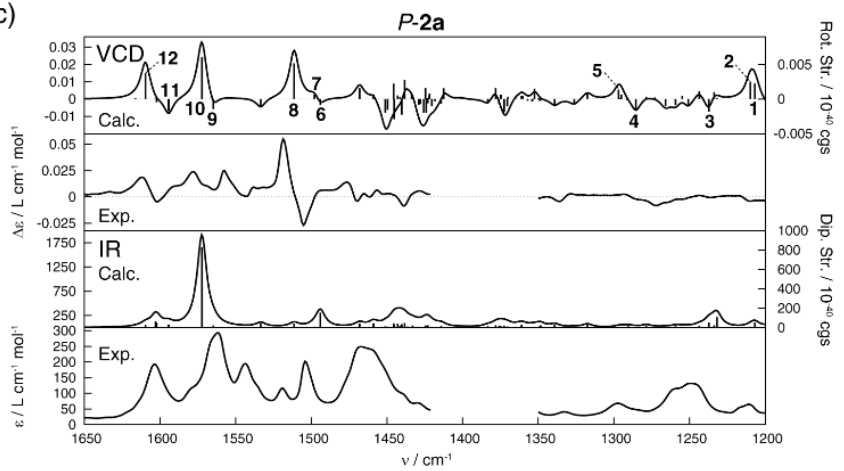

d)



Figure 7. Comparison of experimental (dichloromethane) vs. calculated B3LYP-D3/SV(P) (gas-phase, frequencies scaled by 0.9614$)$ IR and VCD spectra for P-1a (panel a), $P-\mathbf{1 b}(\mathrm{b}), P-\mathbf{2 a}(\mathrm{c})$, and $P-\mathbf{2 b}(\mathrm{d})$. Numbered VCD vibrations correspond to those analyzed in detail. 
Table 3. Selected B3LYP-D3/SV(P) vibrational frequencies along with the corresponding dipole and rotatory strength values in $P$-1a. Compare with Figure 8.

\begin{tabular}{|c|c|c|c|c|}
\hline Label & $v / \mathrm{cm}^{-1}$ & $v($ scaled $) / \mathrm{cm}^{-1}$ & Dip. Str. $/ 10^{-40} \mathrm{cgs}$ & Rot. Str. $/ 10^{-44} \mathrm{cgs}$ \\
\hline 1 & 1254 & 1205 & 5.32 & -7.11 \\
\hline 2 & 1283 & 1233 & 38.16 & -4.12 \\
\hline 3 & 1304 & 1254 & 4.25 & -18.41 \\
\hline 4 & 1323 & 1272 & 19.67 & -13.68 \\
\hline 5 & 1552 & 1492 & 11.70 & -9.11 \\
\hline 6 & 1558 & 1498 & 13.07 & 11.41 \\
\hline 7 & 1570 & 1510 & 1.97 & -5.19 \\
\hline 8 & 1659 & 1595 & 8.70 & -9.69 \\
\hline 9 & 1668 & 1604 & 14.08 & -2.98 \\
\hline 10 & 1675 & 1610 & 2.78 & \\
\hline
\end{tabular}

Table 4. Selected B3LYP-D3/SV(P) vibrational frequencies along with the corresponding dipole and rotatory strength values in $P$-2a. Compare with Figure 9.

\begin{tabular}{|c|c|c|c|c|}
\hline Label & $v / \mathrm{cm}^{-1}$ & $v($ scaled $) / \mathrm{cm}^{-1}$ & Dip. Str. $/ 10^{-40} \mathrm{cgs}$ & Rot. Str. $/ 10^{-44} \mathrm{cgs}$ \\
\hline 1 & 1255 & 1207 & 49.46 & 22.45 \\
\hline 2 & 1258 & 1210 & 11.06 & -18.69 \\
\hline 3 & 1287 & 1237 & 56.28 & -16.34 \\
\hline 4 & 1337 & 1286 & 2.97 & 13.55 \\
\hline 5 & 1349 & 1297 & 8.35 & -8.82 \\
\hline 6 & 1554 & 1494 & 154.84 & 6.75 \\
\hline 7 & 1558 & 1498 & 8.36 & 51.51 \\
\hline 8 & 1572 & 1511 & 38.11 & -14.43 \\
\hline 9 & 1628 & 1565 & 23.01 & 60.85 \\
\hline 10 & 1635 & 1572 & 827.32 & -17.62 \\
\hline 11 & 1658 & 1594 & 33.52 & 37.59 \\
\hline 12 & 1674 & 1610 & 30.14 & \\
\hline
\end{tabular}




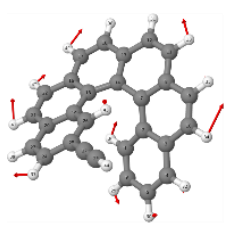

1



6

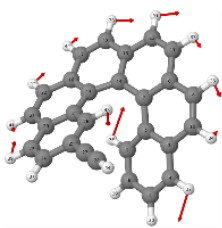

2

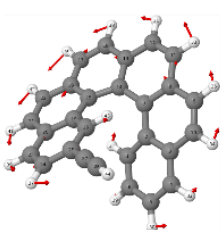

7

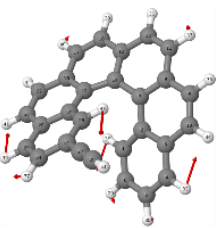

3

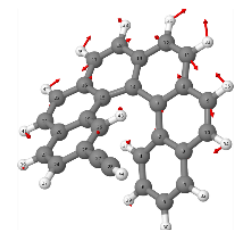

8

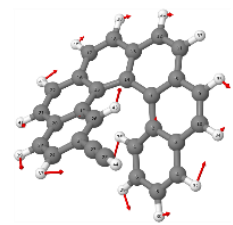

4

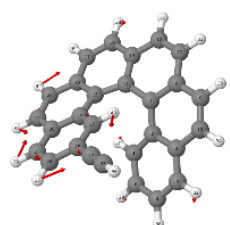

9

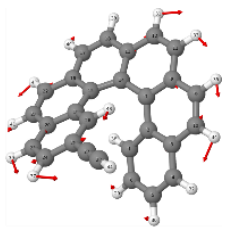

5

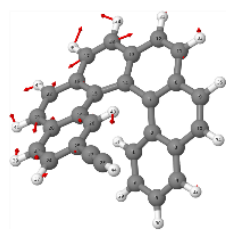

10

Figure 8. Atomic displacements for selected normal modes in 1a.

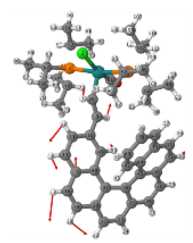

1



7

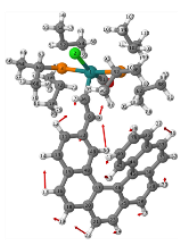

2



8

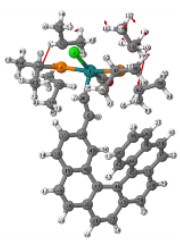

3



9

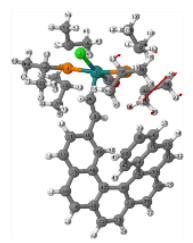

4

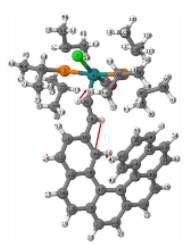

10

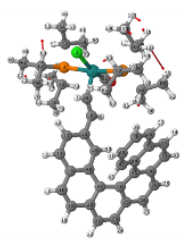

5

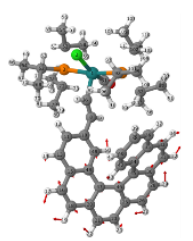

11

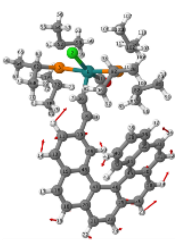

6



12

Figure 9. Atomic displacements for selected normal modes in $\mathbf{2 a}$.

$1492 \mathrm{~cm}^{-1}$, respectively, $\mathrm{g} \sim 4.0 \cdot 10^{-4}$ for $\mathbf{1 a}$ and $8.0 \cdot 10^{-4}$ for $\mathbf{1 b}$ at $1504 \mathrm{~cm}^{-1}$ ).

Not surprisingly, taking into account the large number of degrees of freedom in $\mathbf{2} \mathbf{a}, \mathbf{b}$, calculations of IR and VCD spectra for these systems performed with B3LYP/SV(P) and B3LYP$\mathrm{D} 3 / \mathrm{SV}(\mathrm{P})$ revealed a stronger sensitivity to the molecular structure parameters / geometry optimization method, and consequently yielded less good agreement than for $\mathbf{1} \mathbf{a}, \mathbf{b}$, especially in the case of $\mathbf{2} \mathbf{b}$ (Figure 7 and $\mathrm{SI}$ ). The VCD in the vinyl region is particularly sensitive to the computational model (Figure S2, SI). The quantum-chemical analysis of the computed spectra reveals what effects the organometallic-vinyl fragments have on the helicene VCD signatures. For both $\mathbf{2} \mathbf{a}, \mathbf{b}$ low-intensity VCD bands between $1200 \mathrm{~cm}^{-1}$ and $1350 \mathrm{~cm}^{-1}$ predominantly originate from in-plane and out-of-plane $-\mathrm{CH}$ bending modes within the ruthenium moieties; see atomic displacements for the modes $n^{\circ} 3-5$ in Figure 8 and $n^{\circ} 1-4$ in Figure S4 for $\mathbf{2 a}$ and $\mathbf{2 b}$, respectively. The breathing mode of the helicene still appears just above $1500 \mathrm{~cm}^{-1}$ ( $n^{\circ} 8$ for $\mathbf{2 a}$ and $n^{\circ} 7$ for $\mathbf{2 b}$ ), however it seems the calculated energetic ordering of the peaks in the region is incorrect, likely due to small contributions from the tri-isopropyl phosphine $\mathrm{CCH}$ bends. Agreement with experiment is satisfactory for $\mathbf{2 a}$, but worsens for $\mathbf{2 b}$. Additional bands observed in experiment between
1520 and $1580 \mathrm{~cm}^{-1}$ may indeed be assigned to either 'pure' vinyl $\mathrm{C}=\mathrm{C}$ stretches or $\mathrm{C}=\mathrm{C}$ stretches coupled to the vibrational modes of the helix ( $n^{\circ} 9-10$ and $n^{\circ} 8-11$ for $2 \mathbf{a}$ and $\mathbf{2 b}$, respectively).

\section{Electrochemical behaviour of ruthenium-vinylhelicene complexes $2 \mathrm{a}, \mathbf{b}$}

Chiroptical switches are multifunctional materials that may be useful for a variety of applications such as in molecular electronics, optical displays or for telecommunication purposes. ${ }^{[21]}$ The high MR values at optical wavelengths and intense ECD spectra of $\mathbf{2 a}, \mathbf{b}$ make these helical $\pi$-conjugated molecules very appealing candidates for chiroptical switches due to the presence of the potentially electro-active remote $\mathrm{Ru}$ "-centers. ${ }^{\text {[4a] }}$ Few helicenebased chiroptical switches have been described so far. They are either based on photochromic, ${ }^{[4 \mathrm{~d}-\mathrm{f}]} \operatorname{redox}^{[4 \mathrm{a}, \mathrm{c}, \mathrm{g}, \mathrm{h}]}$ or acid-base ${ }^{[4 \mathrm{~b}, \mathrm{i}, \mathrm{j}]}$ systems. Furthermore, few other examples of electroactive helicene derivatives have been described in the literature. ${ }^{[22]}$ For example, helicene and azahelicenes undergo multi-reduction processes, ${ }^{[22 a, b]}$ and paraquinone- ${ }^{[22 c]}$ or thiophene- [22d] incorporating helicenes can be respectively reduced or oxidized into the corresponding radical anion or cation. Other examples were given by mono- and bis-cobaltocenium fused 
[7]helicenes, ${ }^{[22 e]}$ and recent ferrocenyl-alkynyltetrathia[7] helicenes. ${ }^{[22 f]}$

An important and well-established property of (arylvinyl) $\mathrm{RuCl}(\mathrm{CO})\left(\mathrm{P}^{i} \mathrm{Pr}_{3}\right)_{2}$ complexes is that the $\mathrm{Ru}$ "l center can achieve multistep reversible oxidation/reduction processes, involving the "non-innocent" arylvinyl ligands, at fairly low potential. ${ }^{[7 \mathrm{~b}-\mathrm{i}, 8]}$ In fact, the $\mathrm{RuCl}(\mathrm{CO})\left(\mathrm{P}^{i} \mathrm{Pr}_{3}\right)_{2}$ moiety stabilizes the radical cations (to about the same extent as dialkylamino groups) and the charges are mainly located on the organic arylvinyl fragments. ${ }^{[7 b-i]}$ Cyclic voltammetry (CV) studies of the complex 2a $\left(\mathrm{CH}_{2} \mathrm{Cl}_{2} / \mathrm{NBu}_{4} \mathrm{PF}_{6}, 0.2 \mathrm{M}\right)$ revealed the presence of one chemically and electrochemically reversible oxidation at $E_{1}^{\circ}=+0.173 \mathrm{~V}$ versus the ferrocene/ferrocenium $\left(\mathrm{Fc} / \mathrm{Fc}^{+}\right)$standard, followed by a second irreversible oxidation at $E_{\mathrm{pa}}=+0.781 \mathrm{~V}\left(100 \mathrm{mV} \cdot \mathrm{s}^{-1}\right)($ Table 5). As observed for related $\mathrm{RuCl}(\mathrm{CH}=\mathrm{CHAr})(\mathrm{CO})\left(\mathrm{P}^{i} \mathrm{Pr}_{3}\right)_{2}$ complexes, ${ }^{[7 \mathrm{c}]}$ the wave observed at $E_{1}{ }^{\circ}=+0.173 \mathrm{~V}$ is expected to be a one-electron oxidation affording $[2 a]^{+}\left[P F_{6}\right]^{-}$. It is noteworthy that it takes place at a significantly lower potential than that observed for thiophene-based helicenes $(1.3 \mathrm{~V}),{ }^{[2 \mathrm{~d}]}$ or TTF-based helicene ${ }^{[4 c]}$ rendering the concept of remotely grafting a metal center on a helical $\pi$-conjugated system an easy method to produce helical radical cations. Furthermore, 2a oxidizes more readily than the parent $\mathrm{RuCl}(\mathrm{CH}=\mathrm{CHPh})(\mathrm{CO})\left(\mathrm{P}^{i} \mathrm{Pr}_{3}\right)_{2}$ complex, for which first reversible oxidation potential is observed at $0.280 \mathrm{mV}$ (vs. $\left.\mathrm{Fc} / \mathrm{Fc}^{+}\right) \cdot{ }^{[7 \mathrm{c}]}$

One-electron oxidation of $\mathbf{2 a}$ into $[\mathbf{2 a}]^{*+}$ was monitored by IR spectroscopy in a transparent thin-layer (OTTLE) cell since the characteristic IR stretching band for the $C O$ ligand can be used as an indicator of the degree of intrinsic charge delocalization (metal vs. arylvinyl ligand) on the short vibrational timescale. It is worth noting that the $\mathrm{CO}$ stretching band of $\mathbf{2 a}$ displays a lower frequency $\left(1913 \mathrm{~cm}^{-1}\right)$ compared to the related $\mathrm{RuCl}(\mathrm{CH}=\mathrm{CHPh})(\mathrm{CO})\left(\mathrm{P}^{i} \mathrm{Pr}_{3}\right)_{2}$ complex $\left(1927 \mathrm{~cm}^{-1}\right),{ }^{[7 \mathrm{c}]}$ which indicates that more electron density is transferred from the $\mathrm{Ru}$ ion to the $\pi^{*}$-orbitals of the carbonyl ligand. This illustrates the increased $\pi$-conjugation of the vinyl-helicene ligand with the $\mathrm{Ru}$ center. The formation of the radical cation results in a blue shift of the CO stretch from $1913 \mathrm{~cm}^{-1}$ to $1968 \mathrm{~cm}^{-1}$ (Figure 10b left) and the appearance of new $\mathrm{C}=\mathrm{C}$ bands in the $1640-1520 \mathrm{~cm}^{-1}$ region, certainly due to the modification of the electronic density over the helicene (see ref. [4a]). The slight increase in the energy of the $\mathrm{CO}$ stretch is assigned to a minor decrease of electron density transferred from the metal ion to the $\pi^{*}$ orbitals of the carbonyl ligand and suggests that the radical cation is largely localized on the helicene fragment. Note that full reversibility was observed upon repetitive oxidation / reduction cycles on the CV timescale. A slightly anisotropic EPR signal $(77 \mathrm{~K})$ was recorded with a $g$-value (2.042) which is similar to that observed for related mono (arylvinyl)ruthenium radical cation complexes ( $g$-value = 2.033). ${ }^{[4,7 c]}$ The $g$-value and the $v(\mathrm{CO})$ shift suggest that the vinylhelicene moiety of $\mathbf{2 a}$ is a "non-innocent" ligand that bears an important part of the spin density in $[\mathbf{2 a}]^{\bullet+}$.

UV-vis/NIR spectroelectrochemical studies in an OTTLE cell revealed a slight decrease in intensity of high energy bands (< $480 \mathrm{~nm}$ ), the appearance of sets of structured absorptions at $\sim 500$ $\mathrm{nm}$, and two lower-energy absorption bands at $\sim 630 \mathrm{~nm}$ and $\sim 1000 \mathrm{~nm}$ upon oxidation at $0.4 \mathrm{~V}$ vs. $\mathrm{Fc} / \mathrm{Fc}^{+}$(Figure 11a). Here again, full reversibility was observed upon several oxidation / reduction cycles. ${ }^{[4 a]}$ The experimentally observed features are well reproduced by TDDFT calculations (Figure S6, SI).

To gain a deeper insight into the formation of oxidized species, a quantum-chemical analysis of the electronic structure of the radical cation species $[2 a]^{*+}$ was performed with $B 3 L Y P / S V(P)$ at $\mathrm{BP} / \mathrm{SV}(\mathrm{P})$ optimized geometries. The plot of the electron spin density clearly shows that the unpaired charge density is not only localized on the metal ion but also spread out over the helicene $\pi$ ligand (Figure 10c left, Figure S7).

With two redox-active moieties the bis- $\mathrm{Ru}$ "-vinylhelicene complex $\mathbf{2} \mathbf{b}$ emerges as an appealing platform to investigate the impact of multi-oxidation processes on the chiroptical properties of the [6] helicene fragment. Two consecutive reversible one-electron oxidation waves were observed in $\mathrm{CH}_{2} \mathrm{Cl}_{2}$ at $E_{1}^{\circ}=0.146 \mathrm{~V}$ and $E_{2}^{\circ}$ $=0.285 \mathrm{~V}$, versus the $\mathrm{Fc} / \mathrm{Fc}^{+}$standard, accompanied by a third chemically irreversible wave at ca. $E_{\mathrm{pa}}=0.830 \mathrm{~V}\left(100 \mathrm{mV} \cdot \mathrm{s}^{-1}\right)$ (Table 5). The appearance of the first two waves, instead of one, separated by $\sim 130 \mathrm{mV}$ suggests a stepwise oxidation of the redox-active bis-ruthenium-based helicene $\mathbf{2 b}$. The potential splitting and the lowering of the first oxidation potential with respect to mono-metallic species $2 \mathrm{a}\left(E_{1}^{\circ}=0.173 \mathrm{~V}\right)$ provide first piece of evidence for electronic interaction between the two metal centers via the $\pi$-helicene bridge (although solvation energy changes or ion pairing may also be evoked). ${ }^{[8 a]}$ Note that the two oxidation potentials $\left(E_{1}^{\circ}=0.146 \mathrm{~V}, E_{2}^{\circ}=0.285 \mathrm{~V}\right)$ are too close to obtain $[\mathbf{2 b}]^{\bullet+}$ in a pure form due to substantial comproportionation. However, a constant $K_{\mathrm{c}}=234$ is estimated and corresponds to the presence of more than $90 \%$ of the mono-radical cation.

The formation of $[\mathbf{2 b}]^{++}$and $[\mathbf{2} \mathbf{b}]^{2+}$ was also monitored by IR spectroscopy in an OTTLE cell (Figure 10b right). The monooxidation of the complex $\mathbf{2 b}$, displaying one CO stretch at 1911 $\mathrm{cm}^{-1}$, results in two $\mathrm{CO}$ stretches at 1913 and $1965 \mathrm{~cm}^{-1}$ of identical intensities that are testimonies of two different ruthenium centers into $[\mathbf{2} \mathbf{b}]^{\bullet+}$. Upon the second oxidation, these two bands disappear and a new $v(\mathrm{CO})$ at $1968 \mathrm{~cm}^{-1}$ grows up. It is tempting to assign the first spectrum to the mono-radical cation $[\mathbf{2 b}]^{++}$and the second one to the fully oxidized complex $[\mathbf{2 b}]^{2+}$. A slightly anisotropic EPR signal $(77 \mathrm{~K})$ was recorded for $[\mathbf{2 b}]^{0+}$ with a $g$ value (2.046) which is similar to that of bis-ruthenium(arylvinyl) radical cation complexes $(g$-value $=2.033) .{ }^{[\mathrm{d}]}$ Here again, the $g$ value and the rather modest $v(\mathrm{CO})$ shift clearly show that the vinylhelicene moiety is a "non-innocent" ligand, bearing an important spin density in $[\mathbf{2 b}]^{++}$and in $[\mathbf{2 b}]^{2+}$.

The two oxidation processes were then followed by UVvis/NIR spectroelectrochemistry. The measurements show that two sets of new bands appear during the first oxidation stage, the first one between 450-600 $\mathrm{nm}$ and a large extended band centered at $950 \mathrm{~nm}$. Upon further oxidation (potential increased from 0.2 to $0.6 \mathrm{~V}$ ( vs. $\mathrm{Fc} / \mathrm{Fc}^{+}$), all these bands $(450-600 \mathrm{~nm}$ and $950 \mathrm{~nm}$ ) disappear and a new band appears at $700 \mathrm{~nm}$ (see Figure 11b). TDDFT calculations performed for the doubly oxidized species of $\mathbf{2} \mathbf{b}$ in both its triplet and open-shell singlet electronic configurations agree satisfactory with the experimental one (Figure S6, SI). Notably, the calculations appear also to reproduce correctly the experimentally observed blue-shift of the low-energy NIR absorption band in bis-oxidized $\mathbf{2} \mathbf{b}$ as compared to $[2 a]^{\bullet+}$. The results obtained for the open-shell singlet should be viewed with some caution, however, due to the limitations of 
single-determinant Kohn-Sham DFT with approximate functionals to describe such a spin state.

An analysis of the electronic structure of the mono-oxidized species $[\mathbf{2} \mathbf{b}]^{\bullet+}$ and bis-oxidized species $[\mathbf{2 b}]^{2+}$ in its triplet and open-shell singlet configuration was performed (B3LYP/SV $(\mathrm{P}) / / \mathrm{BP} / \mathrm{SV}(\mathrm{P})$ ). As the plots show (Figure 10c right, Figure S8), the electron spin densities of the mono and doubly oxidized complexes both extend over both metal centers and the helicene ligand, with a sizable spin density in the helical $\pi$-system. (The spin density of the singlet is an artifact of the singledeterminant Kohn-Sham reference and only shown for purposes of analysis.) The extensive delocalization of the two unpaired orbitals into the $\pi$-system appears to create a small region of overlap in the center of the molecule (Figure S8). According to the DFT calculations the open-shell singlet and triplet states of the doubly oxidized species of $\mathbf{2} \mathbf{b}$ are practically degenerate, indicating that bis-radical oxidized species $[\mathbf{2} \mathbf{b}]^{2+}$ may exist as an equilibrium mixture of both spin states, and that the direct electronic coupling between the metal centers is weak. Furthermore, the distance between the two Ru centers measured from the $X$-ray structure (Figure 1, $10.525 \AA$ ) is quite large. On the other hand, the extensive delocalization of the unpaired orbitals into the helicene $\pi$-system means that a chain of $\pi$-orbital interactions may link one metal center with the other electronically without necessarily leading to a sizable singlet-triplet energy gap.

\section{Redox chiroptical switching}

Having established that $\mathbf{2} \mathbf{a}, \mathbf{b}$ undergo reversible oxidation processes, the next step towards electrochemical chiroptical switches was to investigate whether these redox processes impact their chiroptical behavior. The ECD spectra of $P$-2a and $P$ $[2 a]^{\bullet+}\left[\mathrm{PF}_{6}\right]^{-}$in dichloroethane (DCE) have a similar shape (Figure 12a), but two features are noteworthy. The oxidation of $P-2 a$ results in a decrease of the ECD-active bands at $340 \mathrm{~nm}(\Delta(\Delta \varepsilon)=$ $-45 \mathrm{M}^{-1} \mathrm{~cm}^{-1}$ ) and the appearance of new broad CD-active bands (of positive sign for the $P$-stereoisomer) ranging from $430 \mathrm{~nm}$ to $580 \mathrm{~nm}\left(\Delta(\Delta \varepsilon)=+17 \mathrm{M}^{-1} \mathrm{~cm}^{-1}\right.$ at $\left.500 \mathrm{~nm}\right)$ and in the NIR-region $\left(\Delta(\Delta \varepsilon)=+8.7 \mathrm{M}^{-1} \mathrm{~cm}^{-1}\right.$ at $900 \mathrm{~nm}$, see inset of Figure 12a). Exploiting these differences, along with the reversibility of the oxidation process, allows obtaining an electrochemical chiral switch. Indeed, stepping potentials between -0.4 and $+0.4 \mathrm{~V}$ of a DCE solution of $2 \mathrm{a}\left(0.2 \mathrm{M}, \mathrm{n}-\mathrm{Bu}_{4} \mathrm{PF}_{6}\right)$ in an electrochemical cell lead to a reversible modulation of the CD signals both at 340 and $500 \mathrm{~nm}$ (Figure 12c). Remarkably, this redox chiroptical switch can be used at a high energy wavelength, which belongs to the classic CD-active fingerprint of helicene derivatives, and at a low energy wavelength, which is due to the presence of the Ru-center.

The modifications of ECD spectra for $P-2 a$ and $P-[2 a]^{*+}$ that appear in the UV-vis and NIR region are well reproduced by theory, as illustrated in Figure 12b. To establish the origin of the changes in CD-bands of $2 \mathbf{a}$ appearing upon metal oxidation, selected dominant excitations of $[2 \mathbf{a}]^{\circ+}$ have been analyzed in detail (Table 6, Figure 13). Note that for the oxidized species there is more mixing of different orbital pairs in the calculated TDDFT BHLYP excitations, which is reflected in the presence of a larger number of particular MO-pair contributions per excitation with smaller percent values. Due to relaxation and spin polarization, the SOMO of the radical ion itself, MO206 / $\alpha$, is not a good approximation of the unpaired spin density. However, its unoccupied counterpart MO206 / $\beta$ in the radical ion reflects closely the plot of the HOMO of the neutral species as well as the calculated spin density distribution and represents the 'hole' in the $\beta$-spin density (compare Figure S9, SI).

The analysis of dominant labeled excitations of [2a $]^{\bullet+}$ in terms of individual MO pairs predominantly links the differences in the spectra of the neutral vs. oxidized $2 \mathbf{a}$ to $i$ ) absence or presence of contributions involving the MO206 / $\beta$ orbital representing 'electron hole' created upon oxidation, and ii) to a change in the character of $\mathrm{MO} 206 / \alpha$ of $[\mathbf{2 a}]^{\bullet+}$ compared to MO206 of $\mathbf{2 a}$ (HOMO, Figure $4 \mathrm{a})$. For example, the positive NIR ECD band in $[2 \mathbf{a}]^{\circ+}$ is caused by excitation $\mathrm{n}^{\circ} 1$ calculated at $920 \mathrm{~nm}$ and assigned as $\pi-\pi^{*}$ intraligand / ligand-to-metal charge transfer (IL / LMCT) transition from helicene-centered $\beta$-occupied MOs (MO204, MO205, MO202, Figure 13) to the metal-vinyl-centered MO206 / $\beta$. Additional positive CD intensity appearing around $500 \mathrm{~nm}$ upon oxidation of $2 a$ results mainly from two excitations. One of these, $n^{\circ} 8$ at 514 $\mathrm{nm}$, is a $\pi-\pi^{*}$ excitation within the helicene $\pi$-system involving, among other orbital transitions, MO206 / $\alpha$ to MO208 / $\alpha$. The other excitation $\mathrm{n}^{\circ} 14$ at $408 \mathrm{~nm}$, is partially assigned as a helicene $\pi-\pi^{*}$ transition involving MO204 / $\alpha$ to MO208 / $\alpha$, and it is enhanced by a participation of Ru orbital (MO206 / $\alpha$ to MO208 / $\alpha$ ) and affords an additional large contribution of metal-to-metal / metal-to-ligand charge transfer (MM / MLCT) (MO197 / $\beta$ to M0206 / $\beta$ ), which again involves the 'electron hole' orbital of $[2 a]^{\bullet+}$. A decrease of the intensity of the ECD band at $340 \mathrm{~nm}$ observed experimentally upon oxidation of $\mathbf{2 a}$ seems to be due to a change in the character of the underlying dominant electronic excitation. The positive intense band of $\mathbf{2} \mathbf{a}$ originates from a $\pi-\pi^{*}$ transition localized in the $\pi$-conjugated system of the helicene moiety $\left(n^{\circ} 6\right.$, vide supra). In the case of $[2 \mathbf{a}]^{\circ+}$ the excitation has LMCT character with some metal-to-metal contributions ( $\mathrm{n}^{\circ} 24$, MO194 / $\beta$ to MO206 / $\beta$ : $14 \%$ and MO200 / $\beta$ to MO206 / $\beta$ : 13\%).

The first oxidation stage of $P-\mathbf{2 b}$ leads to very similar modifications of its ECD spectrum as in the case of $P$-2a (Figure 14a). A visible decrease of the ECD-active bands at 390 and 440 $\mathrm{nm}$ is observed $\left(\Delta(\Delta \varepsilon)=40\right.$ and $14 \mathrm{M}^{-1} \mathrm{~cm}^{-1}$, respectively) along with the appearance of new broad CD intensities centered at 500 $\mathrm{nm}\left(\Delta(\Delta \varepsilon)=20 \mathrm{M}^{-1} \mathrm{~cm}^{-1}\right)$ and at $950 \mathrm{~nm}\left(\Delta(\Delta \varepsilon)=4 \mathrm{M}^{-1} \mathrm{~cm}^{-1}\right)$. Likewise, the bis-vinyl-Ru species $\mathbf{2} \mathbf{b}$ also behaves as an electrochemical chiroptical switch at $500 \mathrm{~nm}$ upon stepping potentials between -0.2 and $+0.2 \mathrm{~V}$ (Figure $14 \mathrm{~b}$ ) by performing $M$ $(-)-\mathbf{2 b} \leftrightarrow M-(-)-[\mathbf{2} \mathbf{b}]^{\bullet+}$ reversible interconversion. Upon further oxidation (potential of $0.6 \mathrm{~V}$ ), recovery of intensity of the main positive CD-active band along with a slight blue-shift comparing to $P-\mathbf{2 b} /[\mathbf{2 b}]^{\circ+}$ can be noticed; all lower-energy bands $(450-600 \mathrm{~nm}$ and $950 \mathrm{~nm}$ ) disappear and a new band appears at $700 \mathrm{~nm}$ (Figure S10, SI). ECD spectrum calculated for doubly oxidized species of $\mathbf{2} \mathbf{b}$ in the singlet and triplet spin configurations reveals satisfactory agreement with experiment (Figure S10, SI). In particular, the energetic position of the positive NIR CD band appears to be correctly reproduced. As quantum-chemical analysis shows the corresponding dominant excitations can be assigned as $\pi-\pi^{*}$ IL / LMCT transition from helicene-centered $\beta$ occupied MOs to the metal-vinyl-centered MOs representing double 'electron hole' created upon oxidation.

Table 5. Electrochemical data of complexes $\mathbf{2 a}, \mathbf{2} \mathbf{b} .^{\text {[a] }}$ 


\begin{tabular}{|c|c|c|c|}
\hline & $\mathrm{E}_{1 / 2}{ }^{0 /+}(\mathrm{V})$ & $\mathrm{E}_{1 / 2}{ }^{+/ 2+}(\mathrm{V})$ & $\mathrm{E}_{1 / 2}{ }^{2+/ 3+}(\mathrm{V})$ \\
\hline $\mathbf{2 a}$ & 0.173 & $0.781^{\mathrm{b}]}$ & \\
$\mathbf{2 b}$ & 0.146 & 0.285 & $0.830^{[\mathrm{b}]}$ \\
& & & \\
\hline
\end{tabular}

[a] Data in $\mathrm{CH}_{2} \mathrm{Cl}_{2} / 0.2 \mathrm{M} \mathrm{NBu}_{4} \mathrm{PF}_{6}$ at room temperature. Potentials are calibrated against the internal $\mathrm{Fc} / \mathrm{Fc}^{+}$couple which is set as $0.00 \mathrm{~V}$. ${ }^{[b]}$ Peak potential of an irreversible process at $\mathrm{V}(0.1 \mathrm{~V} / \mathrm{s})$.

\section{Conclusion}

Introducing one or two heavy transition-metal centers such as ruthenium on a conjugated lateral substituent allows to extend the potential of helicene derivatives for chiroptical materials considerably. The presence of remote metal ions not only remarkably enhances the unique chiroptical behavior of helicenes, but also endows these helical frameworks with novel properties enabling to obtain the first purely helicene-based electrochemically triggered chiroptical switch. First-principles calculations of optical rotations and ECD spectra for the neutral and oxidized species yield in general good agreement with experiment, showing how the participation of the metal-ligands fragment in the conjugated helicene $\pi$-system alters the corresponding optical and spectral properties. VCD spectra of these organometallic ruthenium-vinylhelicene species constitute the first examples of VCD observed for metal-based helicenes and demonstrate typical helicenes signatures with additional features originating from the substituent and increased intensities due to the metallic character. The hitherto unprecedented molecular engineering of helicene derivatives, which is simple from a synthetic point of view, opens new perspectives in the design of chiral multifunctional materials. 
a)
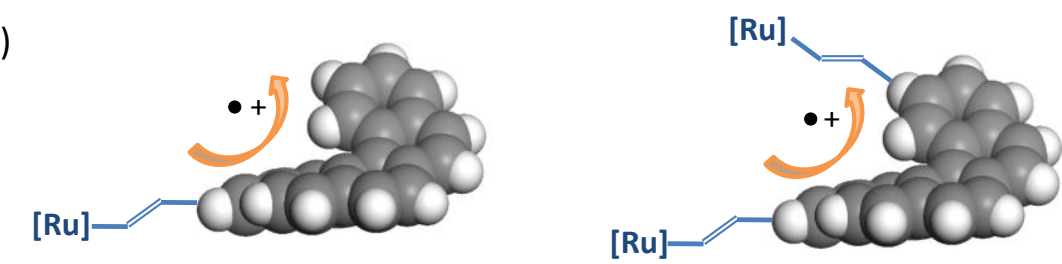

b)
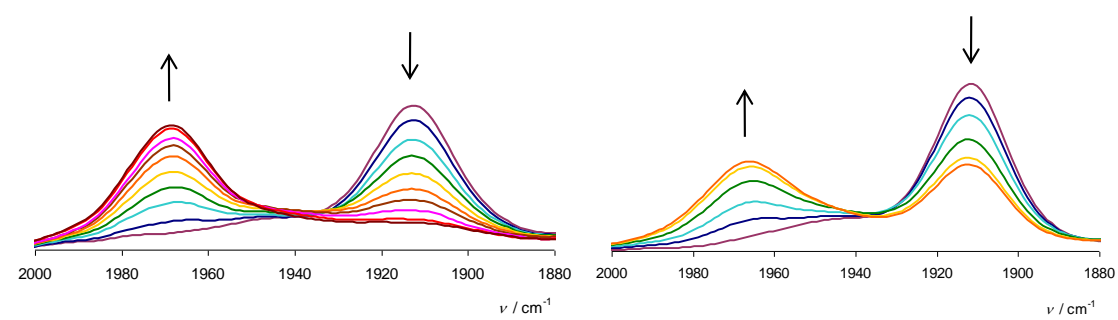

c)

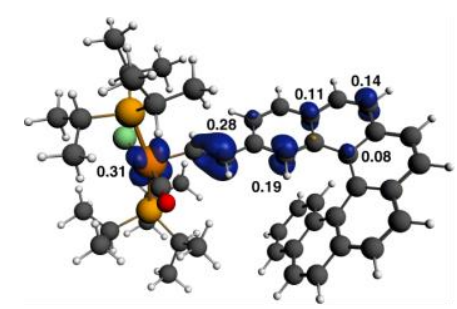

$[2 \mathrm{a}]^{++}$

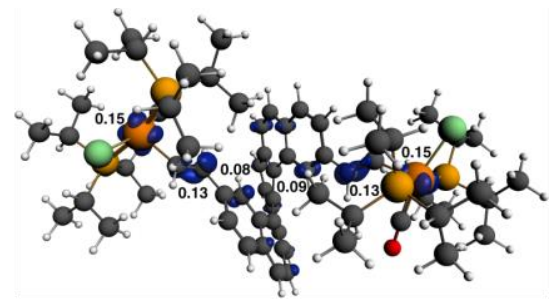

$[2 b]^{++}$
$\Delta \rho>0$

Figure 10. a) Schematic representation of helical radical cation grafted with one or two conjugated metal centers. b) IR region of the $v(\mathrm{CO})$ stretch upon mono-oxidation of $\mathbf{2 a}$ and $\mathbf{2 b}$. c) B3LYP/SV(P) electron spin density, $\Delta \rho=\rho^{\alpha}-\rho^{\beta}(0.005 \mathrm{au})$, in $[\mathbf{2 a}]^{+}$and $[\mathbf{2 b}]^{+}$. Numbers listed are fractions of the total integrated spin density obtained from Mulliken decomposition of $\Delta \rho$. Compare SI.
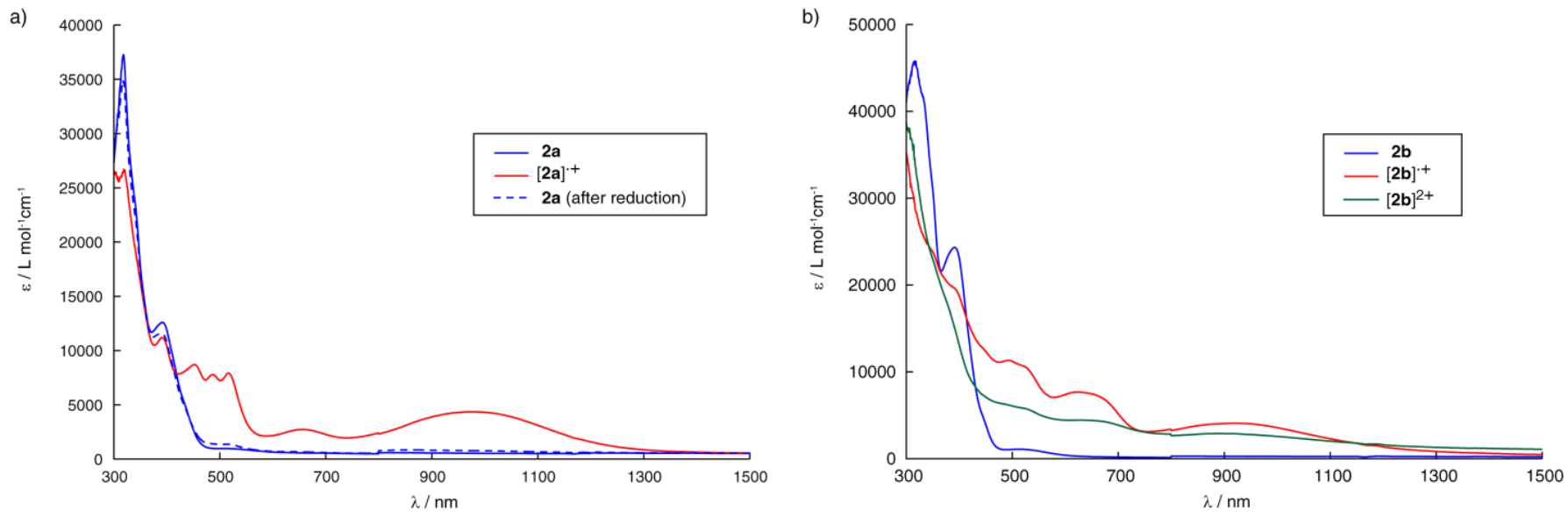

Figure 11. UV-vis/NIR spectroelectrochemistry: a) oxidation at $0.4 \mathrm{~V}\left(\mathrm{vs}\right.$. Fc/Fc ${ }^{+}$) of complex $2 \mathrm{a}$ in $\mathrm{DCE} / 0.2 \mathrm{M}\left[\mathrm{NBu}_{4}\right]^{+}[\mathrm{PF}]^{-}$at r.t., followed by reduction at $-0.4 \mathrm{~V}\left(\mathrm{vs}\right.$. Fc/Fc ${ }^{+}$), and b) first and second oxidation of complex $\mathbf{2 b}$ in $\mathrm{DCE} /\left[\mathrm{NBu}_{4}\right]^{+}\left[\mathrm{PF}_{6}\right]^{-}$at r.t.. 
a)



c)

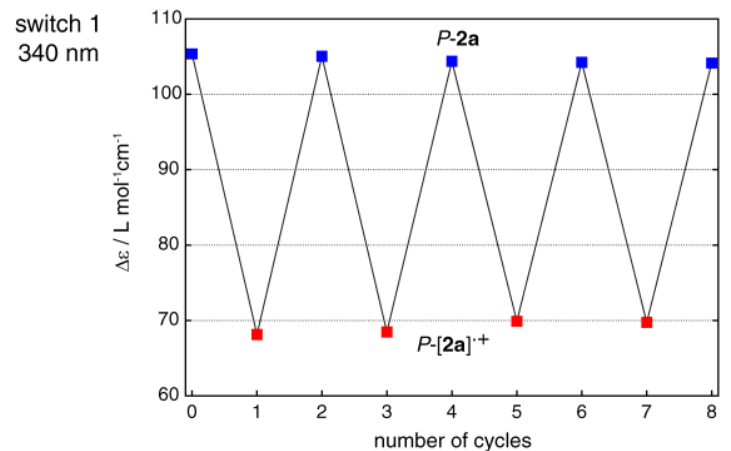

b)



switch 2 $500 \mathrm{~nm}$

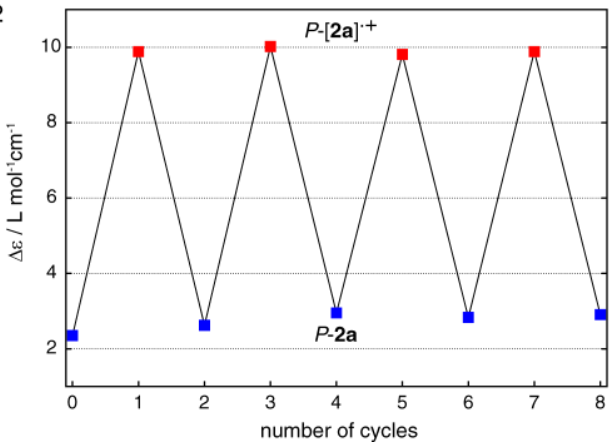

Figure 12. a) Experimental CD spectra of $P-(+)-$ and $M-(-)$ enantiomers of $2 \mathrm{a}$ and of their oxidized (DCE, r.t.) species [2a] $]^{+}$. Inset: NIR CD spectra of $P-(+)-2 \mathbf{a}$ and $P-(+)-[\mathbf{2 a}]^{+}$. b) Calculated BHLYP/SV(P) TDDFT ECD spectra of $P-(+)-2 \mathbf{a}$ and $P-(+)-[\mathbf{2 a}]^{+}$. No spectral shift has been applied. Numbered excitations correspond to those analyzed in detail in Table 1 and Table 6. c) Dual redox chiroptical switching $P-(+)-2 a \leftrightarrow P-(+)-[2 a]^{++}$observed by ECD spectroscopy at 340 and $500 \mathrm{~nm}$.

Table 6. Selected excitations along with occupied (occ) - unoccupied (unocc) MO pair contributions (greater than 10\%) of $P$-[2a] $]^{+}$.

\begin{tabular}{|c|c|c|c|c|c|c|}
\hline Excitation & $E / \mathrm{eV}$ & $f$ & $R / 10^{-40} \mathrm{cgs}$ & occ no. & unocc no. & $\%$ \\
\hline$\# 1$ & 1.35 & 0.1482 & 133.15 & $204 / \beta$ & $206 / \beta$ & 42.5 \\
\hline & & & & $205 / \beta$ & $206 / \beta$ & 19.3 \\
\hline$\# 8$ & & & & $202 / \beta$ & $206 / \beta$ & 15.0 \\
\hline$\# 14$ & 3.41 & 0.0591 & 47.37 & $206 / \alpha$ & $208 / \alpha$ & 15.6 \\
\hline & 3.04 & 0.1607 & 102.11 & $197 / \beta$ & $206 / \beta$ & 25.1 \\
\hline$\# 24$ & & & & $204 / \alpha$ & $208 / \alpha$ & 11.5 \\
\hline & 3.59 & 0.1492 & 157.68 & $194 / \beta$ & $206 / \beta$ & 11.3 \\
\hline & & & & $200 / \beta$ & $206 / \beta$ & 14.4 \\
\hline
\end{tabular}



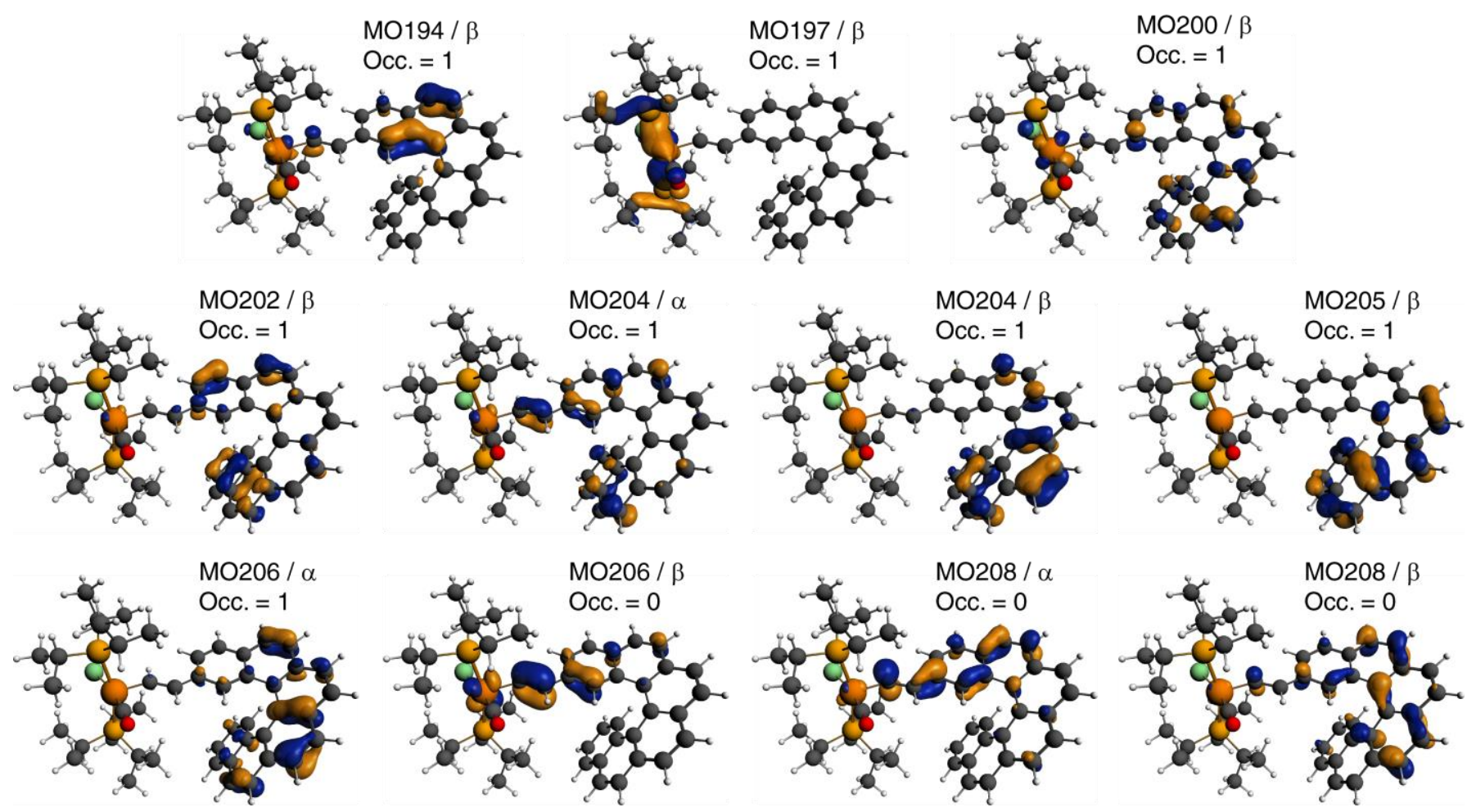

Figure 13. Isosurfaces $(0.05 \mathrm{au})$ of MOs involved in selected transitions of [2a] $]^{+}$.

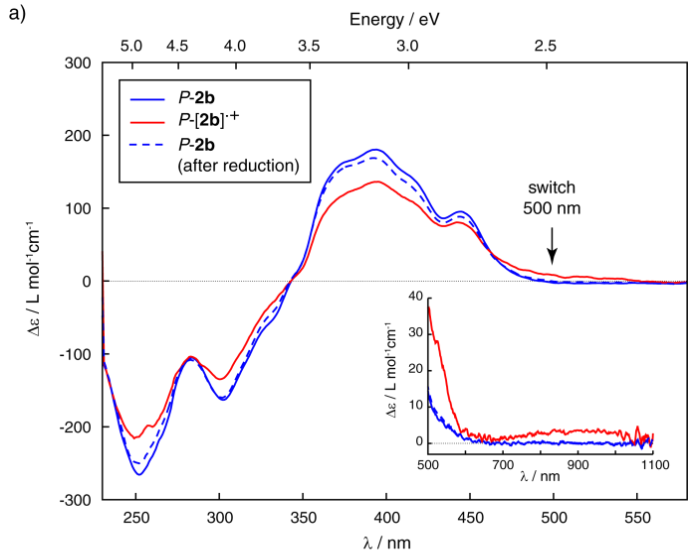

b)

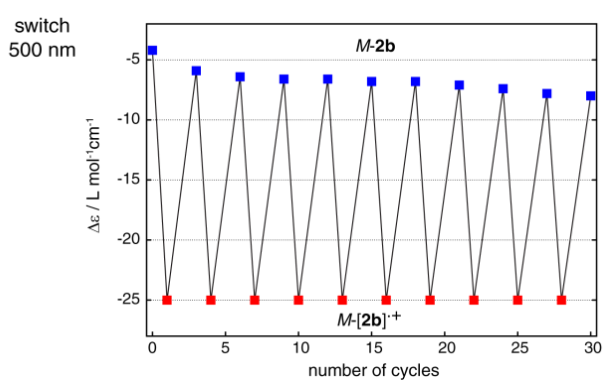

Figure 14. a) Experimental CD spectra of enantiopure $P-(+)-2 \mathbf{b}$ and of its oxidized (DCE, r.t.) species $P-(+)-[\mathbf{2 b}]^{+}$. Dashed line indicates CD spectra for $P-(+)-2 \mathrm{~b}$ obtained via reduction of $P-(+)-$

$[\mathbf{2 b}]^{+}$. Inset: NIR CD spectra of $P-(+)-2 \mathbf{b}$ and $P-(+)-[\mathbf{2 b}]^{++}$. b) Redox chiroptical switching $M-(-)-\mathbf{2 b} \leftrightarrow M-(-)-[\mathbf{2 b}]^{++}$observed by CD spectroscopy at $500 \mathrm{~nm}$. Compare Figure S10, SI.
General remarks

All experiments were performed under argon atmosphere using standard Schlenk techniques. Commercially available reagents were used as received without further purification. Solvents were freshly distilled under argon from sodium/benzophenone (tetrahydrofuran) or from phosphorus pentoxide (dichloromethane). Irradiations were performed using a Heraeus TQ 150 mercury vapor lamp. Preparative separations were performed by gravity column chromatography on silica gel (Merck Geduran 60, 0.063-0.200 mm) in 10-20 cm columns. ${ }^{1} \mathrm{H},{ }^{13} \mathrm{C}$, and ${ }^{31} \mathrm{P}$ NMR spectra were recorded on a Bruker DPX200, AM300, AV400 or AV500 spectrometers. ${ }^{1} \mathrm{H}$ and ${ }^{13} \mathrm{C}$ NMR chemical shifts were reported in parts per million (ppm) relative to $\mathrm{Me}_{4} \mathrm{Si}$ as external standard. ${ }^{31} \mathrm{P}$ NMR downfield chemical shifts were expressed with a positive sign, in ppm, relative to external $85 \% \quad \mathrm{H}_{3} \mathrm{PO}_{4}$ and were decoupled from the proton. Assignment of proton atoms is based on COSY experiment. Assignment of carbon atoms is based on HMBC, HMQC and DEPT-135 experiments. Highresolution mass spectra were obtained on a Varian MAT 311 or ZabSpec TOF Micromass instrument at CRMPO, University of Rennes 1. Elemental analyses were performed by the CRMPO, University of Rennes 1. UV/vis/NIR spectroscopy was conducted on a Varian Cary 5000 spectrometer.

Racemic complex 2a. To a solution of 2-ethynylcarbo[6]helicene ( \pm )-1a (20 mg $0.05 \mathrm{mmol})$ in $2 \mathrm{~mL}$ of $\mathrm{CH}_{2} \mathrm{Cl}_{2}$ under argon was added RuHCICO$\left(\mathrm{P}^{\prime} \mathrm{Pr}_{3}\right)_{2}$ [4] $(27 \mathrm{mg}, 0.05 \mathrm{mmol})$ and the reaction mixture was stirred for $30 \mathrm{~min}$. at room temperature. Dark red single crystals of $( \pm)-2 \mathrm{a}(37 \mathrm{mg}, 90 \%)$ were then grown upon slow evaporation under argon. ${ }^{1} \mathrm{H}$ NMR $\left(400 \mathrm{MHz}, \mathrm{CDCl}_{3}\right) \delta 8.36\left(\mathrm{~d},{ }^{3} \mathrm{~J} \mathrm{H}\right.$ $\mathrm{H}=13.3 \mathrm{~Hz}, 1 \mathrm{H}, \mathrm{RuCH}=\mathrm{CH}), 7.99-7.89(\mathrm{~m}, 6 \mathrm{H}), 7.84\left(\mathrm{~d},{ }^{3} \mathrm{~J}_{\mathrm{H}-\mathrm{H}}=8.5 \mathrm{~Hz}, 1 \mathrm{H}\right), 7.79$ $\left(\mathrm{d},{ }^{3} J_{\mathrm{H}-\mathrm{H}}=8.5 \mathrm{~Hz}, 1 \mathrm{H}\right), 7.76\left(\mathrm{dd}, J=8.00,1.03 \mathrm{~Hz}, 1 \mathrm{H}, \mathrm{H}^{13}\right), 7.70\left(\mathrm{~d},{ }^{3} J_{\mathrm{H}-\mathrm{H}}=\right.$ $\left.8.1 \mathrm{~Hz}, 1 \mathrm{H}, \mathrm{H}^{16}\right), 7.66\left(\mathrm{~d},{ }^{3} \mathrm{~J}_{\mathrm{H}-\mathrm{H}}=8.4 \mathrm{~Hz}, 1 \mathrm{H}, \mathrm{H}^{4}\right), 7.23\left(\mathrm{dd},{ }^{3} J_{\mathrm{H}-\mathrm{H}}=8.5 \mathrm{~Hz},{ }^{4} J_{\mathrm{H}-}\right.$ $\left.\mathrm{H}=1.6 \mathrm{~Hz}, 1 \mathrm{H}, \mathrm{H}^{3}\right), 7.20-7.13\left(\mathrm{~m}, 1 \mathrm{H}, \mathrm{H}^{14}\right), 7.00\left(\mathrm{~s}, 1 \mathrm{H}, \mathrm{H}^{1}\right), 6.72(\mathrm{ddd}, J=8.4$, $\left.6.9,1.35 \mathrm{~Hz}, 1 \mathrm{H}, \mathrm{H}^{15}\right), 5.26\left(\mathrm{dt},{ }^{3} J_{\mathrm{H}-\mathrm{H}}=13.4 \mathrm{~Hz},{ }^{3} \mathrm{~J}_{\mathrm{P}-\mathrm{H}}=2.1 \mathrm{~Hz}, 1 \mathrm{H}, \mathrm{RuCH}=\mathrm{CH}\right)$, 2.70 (sext, $J=7.1 \mathrm{~Hz}, 3 \mathrm{H}, \mathrm{PCH}$ ), 2.60 (sext, $J=7.1 \mathrm{~Hz}, 3 \mathrm{H}, \mathrm{PCH}$ ), 1.34-1.24 (m, $\left.18 \mathrm{H}, \mathrm{PCH}\left(\mathrm{CH}_{3}\right)_{3}\right), 1.18-1.04\left(\mathrm{~m}, 18 \mathrm{H}, \mathrm{PCH}\left(\mathrm{CH}_{3}\right)_{3}\right) .{ }^{31} \mathrm{P} \mathrm{NMR}(162 \mathrm{MHz}$, $\left.\mathrm{CDCl}_{3}\right) \delta 39.39\left(\mathrm{~d},{ }^{3} \mathrm{JP}_{\mathrm{P}-\mathrm{p}}=275 \mathrm{~Hz}\right), 37.40\left(\mathrm{~d},{ }^{3} \mathrm{~J}_{\mathrm{P}-\mathrm{P}}=275 \mathrm{~Hz}\right) .{ }^{13} \mathrm{C}$ NMR $(101 \mathrm{MHz}$, $\left.\mathrm{CDCl}_{3}\right) \delta 202.6\left(\mathrm{t}^{2}{ }^{2} \mathrm{~J}\right.$ P-C $\left.=13 \mathrm{~Hz}, \mathrm{CO}\right), 150.6\left(\mathrm{t},{ }^{2} \mathrm{~J}\right.$ p-C $=10.7 \mathrm{~Hz}, \mathrm{RuCH}=\mathrm{CH}$ ), $135.5(C), 134.4\left(\mathrm{t},{ }^{3} J \mathrm{P}-\mathrm{C}=3 \mathrm{~Hz}, \mathrm{RuCH}=C H\right), 132.8(C), 131.7(C), 131.5(C)$, $131.0(C), 130.7(C), 129.9(C), 129.2(C), 128.2(C), 128.1(C), 127.7(C H)$, $127.6(\mathrm{CH} \times 2), 127.4(\mathrm{CH}), 127.3(\mathrm{CH}), 127.2(\mathrm{CH}), 126.9(\mathrm{CH}), 126.6(\mathrm{CH})$, $126.4(\mathrm{CH}), 126.2(\mathrm{CH}), 125.3(\mathrm{CH}), 124.5(\mathrm{CH}), 124.2(\mathrm{C}), 124.1(\mathrm{CH}), 122.9$ $(\mathrm{CH}), 122.1(\mathrm{CH}), 24.57-23.96\left(\mathrm{CH}^{i} \operatorname{Pr} \times 6\right), 19.94\left(\mathrm{CH}_{3}{ }^{i} \mathrm{Pr} \times 3\right), 19.90\left(\mathrm{CH}_{3}{ }^{i} \mathrm{Pr} \times\right.$ 3), $19.81\left(\mathrm{CH}_{3}{ }^{i} \operatorname{Pr} \times 3\right), 19.56\left(\mathrm{CH}_{3}{ }^{i} \operatorname{Pr} \times 3\right)$. Elemental analysis, calcd. (\%) for $\mathrm{C}_{47} \mathrm{H}_{59} \mathrm{ClOP}_{2} \mathrm{Ru}$ : C 67.33, H 7.09; found: C 66.89, H 7.30.UV/Vis $\left(2.410^{-5} \mathrm{M}\right.$, $\mathrm{CH}_{2} \mathrm{Cl}_{2}$ ): 318 (36600), 334 (25500), 342 (22000), 350 (19350), 390 (11300), 530 (690).

\section{Experimental Section}


Racemic complex $\mathbf{2 b}$. To a solution of 2,15-diethynylcarbo[6]helicene ${ }^{5}( \pm)-\mathbf{1 b}$ (20 mg, $0.05 \mathrm{mmol}$ ) in $2 \mathrm{~mL}$ of $\mathrm{CH}_{2} \mathrm{Cl}_{2}$ under argon was added $\mathrm{RuHCICO}\left(\mathrm{P}^{\prime} \mathrm{Pr}_{3}\right)$ [4] $(50 \mathrm{mg}, 0.1 \mathrm{mmol})$ and the reaction mixture was stirred for $30 \mathrm{~min}$. at room temperature. Dark red single crystals of $( \pm)-2 b(56 \mathrm{mg}, 80 \%)$ were then grown upon slow evaporation under argon. ${ }^{1} \mathrm{H}$ NMR $\left(300 \mathrm{MHz}, \mathrm{CD}_{2} \mathrm{Cl}_{2}\right) \delta 8.21\left(\mathrm{~d},{ }^{3} \mathrm{~J}_{\mathrm{H}}\right.$ $\mathrm{H}=13.3 \mathrm{~Hz}, 2 \mathrm{H}, \mathrm{RuCH}=\mathrm{CH}), 7.82(\mathrm{~s}, 4 \mathrm{H}), 7.69(\mathrm{~s}, 4 \mathrm{H}), 7.47\left(\mathrm{~d},{ }^{3} \mathrm{~J}_{\mathrm{H}-\mathrm{H}}=8.4 \mathrm{~Hz}\right.$ $\left.2 \mathrm{H}, \mathrm{H}^{4}\right), 7.07\left(\mathrm{dd}, \mathrm{J}=8.4,1.3 \mathrm{~Hz}, 2 \mathrm{H}, \mathrm{H}^{3}\right), 6.90\left(\mathrm{~s}, 2 \mathrm{H}, \mathrm{H}^{1}\right), 5.16\left(\mathrm{dt},{ }^{3} J_{\mathrm{H}-\mathrm{H}}=13.4\right.$ $\left.\mathrm{Hz},{ }^{3} \mathrm{~J}_{\mathrm{P}-\mathrm{H}}=2.1 \mathrm{~Hz}, 2 \mathrm{H}, \mathrm{RuCH}=\mathrm{CH}\right), 2.58$ (sext, $J=7.1 \mathrm{~Hz}, 6 \mathrm{H}, \mathrm{PCH}\left(\mathrm{CH}_{3}\right)_{3}$ ), 2.48 (sext, $\left.J=7.1 \mathrm{~Hz}, 6 \mathrm{H}, \mathrm{PCH}\left(\mathrm{CH}_{3}\right)_{3}\right), 1.34-1.24\left(\mathrm{~m}, 36 \mathrm{H}, \mathrm{PCH}\left(\mathrm{CH}_{3}\right)_{3}\right), 1.18$ $1.04\left(\mathrm{~m}, 36 \mathrm{H}, \mathrm{PCH}\left(\mathrm{CH}_{3}\right)_{3}\right){ }^{31} \mathrm{P} \mathrm{NMR}\left(162 \mathrm{MHz}, \mathrm{CD}_{2} \mathrm{Cl}_{2}\right) \delta 39.2\left(\mathrm{~d},{ }^{3} J_{\mathrm{P}-\mathrm{P}}=275 \mathrm{H}\right)$ $36.48\left(\mathrm{~d},{ }^{3} \mathrm{~J}\right.$ P-P $\left.=275 \mathrm{~Hz}\right) .{ }^{13} \mathrm{C}$ NMR $\left(75 \mathrm{MHz}, \mathrm{CD}_{2} \mathrm{Cl}_{2}\right) \delta 203.1\left(\mathrm{t},{ }^{2} J_{\mathrm{P}-\mathrm{C}}=13.2 \mathrm{~Hz}\right.$ CO), $150.6\left(t,{ }^{2} J\right.$ P-C $\left.=10.9 \mathrm{~Hz}, \mathrm{RuCH}=\mathrm{CH}\right), 135.5(C), 135.1\left(\mathrm{t},{ }^{3} J_{\mathrm{P}-\mathrm{C}}=3.3 \mathrm{~Hz}\right.$ $\mathrm{RuCH}=\mathrm{CH}), 132.8(C), 131.5(C), 131.1(C), 129.5(C), 128.6(C), 128.0(C H)$ $127.8(\mathrm{CH}), 127.2(\mathrm{CH}), 126.3(\mathrm{CH}), 124.5(\mathrm{C}), 124.4(\mathrm{CH}), 122.6(\mathrm{CH}), 122.3$ $(\mathrm{CH}), 24.9,24.8,24.7,24.6,24.5,24.4\left(\mathrm{CH}{ }^{i} \mathrm{Pr}\right), 20.2,20.1,20.0,19.7$ $\left(\mathrm{CH}_{3}{ }^{\mathrm{i}} \mathrm{Pr}\right)$. Elemental analysis, calcd. (\%) for $\mathrm{C}_{68} \mathrm{H}_{102} \mathrm{Cl}_{2} \mathrm{O}_{2} \mathrm{P}_{4} \mathrm{Ru}_{2}: \mathrm{C} 60.57, \mathrm{H} 7.62$ found: C 58.98, $\mathrm{H}$ 8.02. UV/Vis (2.5 $\left.10^{-5} \mathrm{M}, \mathrm{CH}_{2} \mathrm{Cl}_{2}\right): 314$ (47400), 330 (43120), 345 (33320), 382 (21600), 344 (4830), 517 (840).

The same procedures were used to prepare enantiopure $P-(+)$ and $M-(-)$ complexes $\mathbf{2} \mathbf{a}, \mathbf{b}$ from $P-(+)$ and $M-(-)$ - complexes $\mathbf{1} \mathbf{a}, \mathbf{b} .^{[4 a]}$

\section{Computational details}

All computations were carried out using DFT with Turbomole package, versions 5.7.1 and 6.5..$^{[23-25]}$ Geometry optimizations employed the BP functional ${ }^{[26-28]}$ with a standard Turbomole split-valence basis set with one set of polarization functions for non-hydrogen atoms, SV(P) ${ }^{[29,30]}$ and a scalar relativistic effective core potential for the Ru atoms. ${ }^{[31]}$ The method is abbreviated as BP/SV(P) in the text. Optical rotation (OR) and circular dichroism (CD) calculations were performed using Time-Dependent DFT (TDDFT) with the BHLYP functional ${ }^{32,33]}$ and the SV(P) basis set. The optical rotation parameters were computed at the sodium line wavelength $\lambda=589.3 \mathrm{~nm}$. The CD calculations reported here cover 120 lowest singlet excited states (180 in the case of doubly oxidized species of $\mathbf{2 b}$ ) to assure that all transitions with a significant rotatory strength in the experimentally observed energy range $(\sim 2.5-5.5 \mathrm{eV}$ for neutral, $\sim 1.0-5.5$ $\mathrm{eV}$ for oxidized species) are included. The simulated spectra shown are the sums of Gaussian functions centered at the vertical excitation energies and scaled using the calculated rotatory strengths as previously described in ref. [34]. For the root mean square width, the parameter of $\sigma=0.2 \mathrm{eV}$ was used in all cases.

To provide additional insight into structure-chiroptical property relationships, geometry optimizations employing dispersion corrections at the semi-empirica DFT-D3 level of theory ${ }^{[12]}$ were carried out using the BP functional with the $\mathrm{SV}(\mathrm{P})$ basis set. This functional / basis set combination is abbreviated as BP$\mathrm{D} 3 / \mathrm{SV}(\mathrm{P})$ in the following. The COnductor-like Screening MOdel (COSMO) $)^{[35-37]}$ was applied in some cases to simulate solvent effects $\left(\mathrm{CH}_{2} \mathrm{Cl}_{2}, \varepsilon=8.9\right)$ with the default parameters of the Turbomole/COSMO implementation. The OR calculations were carried out with the linear response of COSMO surface charges in order to assess importance of solvent effects.

Electron spin density, $\Delta \rho=\rho^{\alpha}-\rho^{\beta}$, in oxidized ruthenium-vinyl-helicene derivatives were analyzed using the B3LYP functional ${ }^{[33,38,39]}$ with SV(P).

Calculations of vibrational circular dichroism (VCD) spectra were performed with Gaussian 09 program $^{[40]}$ with B3LYP/SV(P) and B3LYP-D3/SV(P) following corresponding geometry optimizations with the same methods. The calculated harmonic frequencies were scaled by 0.9614 and the spectra were Lorentzian broadened with a full width at half height of $8 \mathrm{~cm}^{-1}$. A comparison of experimental and simulated B3LYP and B3LYP-D3 IR and VCD spectra for all the systems studied is given in the SI. Both methods were found to perform well for the pristine helicenes. For the metal-vinylhelicene complexes B3LYP-D3 appears, however, to slightly outperform B3LYP, Accordingly, the analysis of selected VCD active vibrations was based on the (TD)DFT-D3 results. Images of atomic displacements for analyzed normal modes were generated with Jmol. ${ }^{[41]}$ The corresponding displacement vectors were scaled by 4

\section{Acknowledgements}

We thank the Ministère de l'Education Nationale, de la Recherche et de la Technologie, and the Centre National de la Recherche Scientifique (CNRS), the ANR (12-BS07-0004METALHEL-01). The theoretical component of this work has received financial support by the National Science Foundation to JA (CHE-1265833) and the Foundation for Polish Science Homing Plus programme co-financed by the European Regional Development Fund under the Operational Programme Innovative Economy to MS. MS is also grateful for financial support from the Ministry of Science and Higher Education in Poland ('Outstanding
Young Scientist' scholarship). MS and JA acknowledge the Center for Computational Research (CCR) at the University at Buffalo for providing computational resources.

Keywords: helicenes - ruthenium complexes • redox switches • chiroptical properties $\cdot$ organometallic complexes



[1] a) R. H. Martin, Angew. Chem. Int. Ed. 1974, 13, 649-659; b) T. J. Katz Angew. Chem. Int. Ed. 2000, 39, 1921-1923; c) A. Urbano, Angew. Chem. Int. Ed. 2003, 42, 3986-3989; d) A. Rajca, M. Miyasaka, in Functional Organic Materials (Eds.: T. J. J. Müller, U. H. F. Bunz), WileyVCH, Weinheim, 2007, pp. 543-577; e) F. Dumitrascu, D. G. Dumitrescu, I. Aron, Arkivoc 2010, 1-32; f) Y. Shen, C. -F. Chen, Chem. Rev. 2012, 112, 1463-1535; f) M. Gingras, Chem. Soc. Rev. 2013, 42 , 1051-1095; g) J. Bosson, J. Gouin, J. Lacour, Chem. Soc. Rev. 2014, 43, 2824-2840; h) N. Saleh, C. Shen, J. Crassous, Chem. Sci. 2014, 5 3680-3694; i) P. Aillard, A. Voituriez, A. Marinetti, Dalton Trans. 2014, 43, 15263-15278.

[2] Selected examples: a) R. Hassey, E. J. Swain, N. I. Hammer, D. Venkataraman, M. D. Barnes, Science 2006, 314, 1437-1439; b) Y. Sawada, S. Furumi, A. Takai, M. Takeuchi, K. Noguchi, K. Tanaka, J. Am. Chem. Soc. 2012, 134, 4080-4083; c) K. E. S. Phillips, T. J. Katz, Jockusch, A. J. Lovinger, N. J. Turro, J. Am. Chem. Soc. 2001, 123, 11899-11907 ; d) T. Kaseyama, S. Furumi, X. Zhang, K. Tanaka, M. Takeuchi, M. Angew. Chem., Int. Ed. 2011, 50, 3684-3687. e) K. Nakamura, S. Furumi, M. Takeuchi, T. Shibuya, K. Tanaka, J. Am. Chem. Soc. 2014, 136, 5555-5558; f) C. Shen, E. Anger, M. Srebro, N. Vanthuyne, K. K. Deol, T. D. Jefferson Jr., G. Muller, J. A. G. Williams, L. Toupet, C. Roussel, J. Autschbach, R. Réau, J. Crassous Chem. Sci. 2014, 5, 1915-1927.

[3] a) Y. Yang, R. C. da Costa, M. J. Fuchter, A. J. Campbell, Nature Photonics 2013, 7, 634-638; b) D. J. Weix, S. D. Dreher, T. J. Katz, J. Am. Chem. Soc. 2000, 122, 10027-10032.

[4] a) E. Anger, M. Srebro, N. Vanthuyne, L. Toupet, S. Rigaut, C. Roussel, J. Autschbach, J. Crassous, R. Réau, J. Am. Chem. Soc., 2012, 134 15628; b) E. Anger, M. Srebro, N. Vanthuyne, C. Roussel, L. Toupet, J. Autschbach, R. Réau, J. Crassous, Chem. Comm. 2014, 50, 2854-2856; c) T. Biet, A. Fihey, T. Cauchy, N. Vanthuyne, C. Roussel, J. Crassous, N. Avarvari, Chem. Eur. J. 2013, 19, 13160-13167; d) J. Nishida, T. Suzuki, M. Ohkita, T. Tsuji, Angew. Chem. Int. Ed., 2001, 40, 3251; e) T. J. Wigglesworth, D. Sud, T. B. Norsten, V. S. Lekhi, N. R. Branda, J. Am. Chem. Soc., 2005, 127, 7272; f) Z. Y. Wang, E. K. Todd, X. S. Meng, J. P. Gao, J. Am. Chem. Soc., 2005, 127, 11552; g) L. Pospisil, L. Bednarova, P. Stepanek, P. Slavicek, J. Vavra, M. Hromadova, H. Dlouha, J. Tarabek, F. Teply, J. Am. Chem. Soc. 2014, 136, 10826; 10829; h) D. Schweinfurth, M. Zalibera, M. Kathan, C. Shen, M. Mazzolini, N. Trapp, J. Crassous, G. Gescheidt, F. Diederich, J. Am. Chem. Soc. 2014, 136, 13045-13052; i) N. Saleh, B. Moore, II, M. Srebro N. Vanthuyne, L. Toupet, J. A. G. Williams, C. Roussel, K. K. Deol, G. Muller, J. Autschbach, J. Crassous, Chem. Eur. J. 2015, 21, 1673-1681; j) P. E. Reyes-Gutierrez, M. Jirasek, L. Severa, P. Novotna, D. Koval, P. Sazelova, J. Vavra, A. Meyer, I. Cisarova, D. Saman, R. Pohl, P. Stepanek, P. Slavicek, B. J. Coe, M. Hajek, V. Kasicka, M. Urbanova, F. Teply, Chem. Comm. 2015, 51, 1583-1586.

[5] a) T. Verbiest, S. Van Elshocht, M. Kauranen, L. Hellemans, J. Snauwaert, C. Nuckolls, T. J. Katz, A. Persoons, Science 1998, 282, 913-915; b) E. Botek, J.-M. André, B. Champagne, T. Verbiest, A. Persoons, J. Chem. Phys. 2005, 122, article number 234713; c) A. Bossi, E. Licandro, S. Maiorana, C. Rigamonti, S. Righetto, G. R. Stephenson, M. Spassova, E. Botek, B. Champagne, J. Phys. Chem. C 2008, 112, 7900-7907; d) C. Díaz, Y. Vesga, L. Echevarria, I. G. Stará, I. Starỳ, E.Anger, C. Shen, M. El Sayed Moussa, N.Vanthuyne, J. Crassous, A. Rizzo, F. E. Hernández, RSC Advances 2015, 5, 1742917437. 
[6] a) L. Norel, M. Rudolph, N. Vanthuyne, J. A. G. Williams, C. Lescop, C. Roussel, J. Autschbach, J. Crassous, R. Réau, Angew. Chem. Int. Ed. 2010, 49, 99-102; b) E. Anger, M. Rudolph, L. Norel, S. Zrig, C. Shen, N Vanthuyne, L. Toupet, J. A. G. Williams, C. Roussel, J. Autschbach, J. Crassous, R. Réau, Chem. Eur. J. 2011, 17, 14178-14198; c) E. Anger, M. Rudolph, C. Shen, N. Vanthuyne, L. Toupet, C. Roussel, J. Autschbach, J. Crassous, R. Réau, J. Am. Chem. Soc. 2011, 133, 38003803; d) C. Shen, E. Anger, M. Srebro, N. Vanthuyne, L. Toupet, C. Roussel, J. Autschbach, R. Réau, J. Crassous, Chem. Eur. J. 2013, 19 16722-16728; e) O. Crespo, B. Eguillor, M. A. Esteruelas, I. Fernandez, J. Garcia-Raboso, M. Gomez-Gallego, M. Martin-Ortiz, M. Olivan, M. A. Sierra, Chem. Comm. 2012, 48, 5328-5330. For a review see ref. $1 \mathrm{~h}$.

[7] Selected: a) H. Werner, M. Esteruelas, H. Otto, Organometallics 1986, 5 , 2295-2299; b) S. Zalis, R. F. Winter, W. Kaim, Coord. Chem. Rev. 2010 254, 1383-1396; c) J. Maurer, M. Linseis, B. Sarkar, B. Schwederski, M. Niemeyer, W. Kaim, S. Zalis, C. Anson, M. Zabel, R. F. Winter, J. Am. Chem. Soc. 2008, 130, 259-268; d) J. Maurer, B. Sarkar, B. Schwederski, W. Kaim, R. F. Winter, S. Zalis, Organometallics 2006, 25, 3701-3712; e) F. Pevny, E. Di Piazza, L. Norel, M. Drescher, R. F. Winter, S. Rigaut, Organometallics 2010, 29, 5912-5918; f) W. Y. Man, J. Xia, N. J. Brown, J. D. Farmer, D. S. Yufit, J. A. K. Howard, S. H. Liu, P. J. Low, Organometallics 2011, 30, 1852-1858; ; g) P. Muecke, M. Zabel, R. Edge D. Collison, S. Clement, S. Zalis, R. F. Winter, J. Organomet. Chem 2011, 696, 3186-3197; h) M. Linseis, S. Zalis, M. Zabel, R. F. Winter, J. Am. Chem. Soc. 2012, 134, 16671-16692; i) E. Wuttke, Y. -M. Hervault, W. Polit, M. Linseis, P. Erler, S. Rigaut, R. F. Winter, Organometallics 2014, 33, 4672-4686.

[ 8] a) K. Costuas, S. Rigaut, S. Dalton Transactions 2011, 40, 5643-5658 b) P. Aguirre-Etcheverry, D. O'Hare, Chem. Rev. 2010, 110, 4839-4864

[9] Selected examples: a) M. Samoc, N. Gauthier, M. P. Cifuentes, F. Paul, C. Lapinte, M. G. Humphrey, Angew. Chem. Int. Ed. 2006, 45, 7376 7379 (2006); b) E. Di Piazza, L. Norel, K. Costuas, A. Bourdolle, O. Maury, S. Rigaut, J. Am. Chem. Soc. 2011, 133, 6174-6176; c) Y. Liu, C. Lagrost, K. Costuas, N. Tchouar, H. Le Bozec, S. Rigaut, Chem Commun. 2008, 6117-6119; d) Y. Tanaka, T. Ishisaka, A. Inagaki, T. Koike, C. Lapinte, M. Akita, Chem. Eur. J. 2010, 16, 4762-4776.

[10] a) M. S. Newman, D. Lednicer, J. Am. Chem. Soc. 1956, 78, 4765-4770 b) M. El Sayed Moussa, M. Srebro, E. Anger, N. Vanthuyne, C. Roussel, C. Lescop, J. Autschbach, J. Crassous, Chirality 2013, 25, 455-465; c) S. Graule, M. Rudolph, N. Vanthuyne, J. Autschbach, C. Roussel, J. Crassous, R. Réau, J. Am. Chem. Soc. 2009, 131, 3183-3185; d) S Graule, M. Rudolph, W. Shen, C. Lescop, J. A. G. Williams, J. Autschbach, J. Crassous and R. Réau, Chem. Eur. J. 2010, 16, 5976 6005 .

[11] a) M. S. Newman, W. B. Lutz, D. Lednicer, J. Am. Chem. Soc. 1955, 77, 3420-3421.

[12] S. Grimme, J. Antony, S. Ehrlich, H. Krieg, J. Chem. Phys. 2010, 132, 154104-154119.

[13] a) M. Srebro, N. Govind, W. A. de Jong, J. Autschbach, J. Phys. Chem A 2011, 115, 10930-10949; b) D. H. Friese, C. Hättig, C. Phys. Chem. Chem. Phys. 2014, 16, 5942-5951; c) M. Srebro, J. Autschbach, J. Chem. Theory Comput. 2012, 8, 245-256.

[14] J. M. Fox, D. Lin, Y. Itagaki, T. Fujita, J. Org. Chem. 1998, 63, 2031 2038.

[15] Note that the results obtained in our previous communication erroneously presented a regioisomer with one of the two Ru-vinylmoieties grafted in position 3 instead of position 2 (see SI in ref. [4a]). Nevertheless, the results and general conclusions were very similar to the correct calculated structure of $\mathbf{2} \mathbf{b}$ described here.

[16] F. Furche, R. Ahlrichs, C. Wachsmann, E. Weber, A. Sobanski, F. Vogtle, S. Grimme, J. Am. Chem. Soc. 2000, 122, 1717-1724.

[17] a) L. Nafie, Vibrational Optical Activity: Principles and Applications, Wiley, 2011; b) L. A. Nafie, in Comprehensive Chiroptical Spectroscopy N. Berova, P. L. Polavarapu, K. Nakanishi, R. W. Woody (eds.), WileyVCH: New York, 2012, Vol. 1, pp 115-146; c) Barron, L. D. Molecula Light Scattering and Optical Activity, Cambridge Univ. Press: Cambridge, U.K., 2nd Ed., 2009; d) T. Wu, X. -Z. You, P. Bour, Coord. Chem. Rev. $2015,284,1-18$

[18] a) T. Bürgi, A. Urakawa, B. Behzadi, K.-H. Ernst, A. Baiker, New. J. Chem. 2004, 28, 332-334; b) S. Abbate, F. Lebon, G. Longhi, F. Fontana,T. Caronna, D. A. Lightner, Phys. Chem. Chem. Phys. 2009, 11,
9039-9043; c) S. Abbate, G. Longhi, F. Lebon, E. Castiglioni, S. Superchi, L. Pisani, F. Fontana, F. Torricelli, T. Caronna, C. Villani, R. Sabia, M. Tommasini, A. Lucotti, D. Mendola, A. Mele, D. A. Lightner, J. Phys. Chem. C 2014, 118, 1682-1695; d) A. H. Pandith, N. Islam, Z. F. Syed, S.-u Rehman, S. Bandaru, A. Anoop, Chem. Phys. Lett. 2011, 516, 199203; e) T. B. Freedman, X. Cao, A. Rajca, H. Wang, L. A. Nafie, J. Phys. Chem. A 2003, 107, 7692-7696; f) C. Herse, D. Bas, F. C. Krebs,T. Bürgi J. Weber, T. Wesolowski, B. W. Laursen, J. Lacour, Angew. Chem. Int Ed. 2003, 42, 3162-3166; g) P. Mobian, C. Nicolas, E. Francotte, T. Bürgi, J. Lacour, J. Am. Chem. Soc. 2008, 130, 6507-6514; h) F. Torricelli, J. Bosson, C. Besnard, M. Chekini, T. Bürgi, , J. Lacour, Angew. Chem. Int. Ed. 2013, 52, 1796-1800; i) V. P. Nicu, J. Neugebauer, S. K. Wolff, E. J. Baerends, Theor. Chem. Account 2008 119, 245-263; j) V. Liégeois, B. Champagne, J. Comput. Chem. 2009, 30 , $1261-$.

[19] See for example G. Grelaud, M. P. Cifuentes, F. Paul, M. G. Humphrey, J. Organometal. Chem. 2014, 751, 181-200

[20] a) Y. He, X. Cao, L. A. Nafie, T. B. Freedman, J. Am. Chem. Soc. 2001 123, 11320-11321; b) S. R. Domingos, A. Huerta-Viga, L. Baij, S Amirjalayer, D. A. E. Dunnebier, A. J. C. Walters, M. Finger, L. A. Nafie, B. de Bruin, W. J. Buma, S. Woutersen, J. Am. Chem. Soc. 2014, 136, 3530-3535 and references therein.

[21] a) J. W. Canary, Chem. Soc. Rev. 2009, 38, 747-756; b) Molecular Switches, B. L. Feringa, W.R. Browne (Eds), Wiley-VCH, 2001; c) D. Li, Z. Y. Wang, D. Ma, Chem. Commun. 2009, 1529-1531; d) Comprehensive Chiroptical Spectroscopy, N. Berova, P. L. Polavarapu, K. Nakanishi, R. W. Woody (eds.), Wiley: Hoboken, 2012, Vol. 2.

[22] a) S. I. Weissman, R. Chang, R. J. Am. Chem. Soc. 1972, 94, 86838684; b) L. Adriaenssens, L. Severa, T. Salova, I. Cisarova, R. Pohl, D. Saman, S. V. Rocha, N. S. Finney, L. Pospisil, P. Slavicek, F. Teply, Chem. Eur. J. 2009, 15, 1072-1076; c) C. A. Liberko, L. L. Miller, T. J. Katz, L. Liu, J. Am. Chem. Soc. 1993, 115, 2478-2482; d) J. K. Zak, M. Miyasaka, S. Rajca, M. Lapkowski, A. Rajca, J. Am. Chem. Soc. 2010 132, 3246-3247; e) A. M. Gilbert, T. J. Katz, W. E. Geiger, M. P. Robben, A. L. Rheingold, J. Am. Chem. Soc. 1993, 115, 3199-3211; f) F. RoseMunch, M. Li, E. Rose, J. -C. Daran, A. Bossi, E. Licandro, P. R. Mussini, Organometallics 2012, 31, 92-104.

[23] TURBOMOLE V5.7.1 2005 and V6.5 2013, a development of University of Karlsruhe and Forschungszentrum Karlsruhe $\mathrm{GmbH}$, 1989-2007, TURBOMOLE $\mathrm{GmbH}$, since 2007; available from http://www.turbomole.com

[24] R. Ahlrichs, M. Bär, M. Häser, H. Horn, C. Kölmel, Chem. Phys. Lett. 1989, 162, 165

[25] F. Furche, R. Ahlrichs, C. Hättig, W. Klopper, M. Sierka, F. Weigend, WIREs Comput. Mol. Sci. 2014, 4, 91.

[26] A. D. Becke, Phys. Rev. A 1988, 38, 3098-3100.

[27] J. P. Perdew, Phys. Rev. B 1986, 33, 8822-8824.

[28] J. P. Perdew, Phys. Rev. B 1986, 34, 7406.

[29] A. Schäfer, H. Horn, R. Ahlrichs, J. Chem. Phys. 1992, 97, 2571.

[30] K. Eichkorn, F. Weigend, O. Treutler, R. Ahlrichs, Theor. Chem. Acc. 1997, 97, 119

[31] D. Andrae, U. Häußermann, M. Dolg, H. Stoll, H. Preuß, Theoret. Chim. Acta 1990, 77, 123.

[32] A. D. Becke, J. Chem. Phys. 1993, 98, 1372.

[33] C. Lee, W. Yang, R. G. Parr, Phys. Rev. B 1988, 37, 785.

[34] J. Autschbach, T. Ziegler, S. J. A. van Gisbergen, E. J. Baerends, J. Chem. Phys. 2002, 116, 6930.

[35] A. Klamt, G. J. Schüürmann, J. Chem. Soc., Perkin Trans. 21993, 799.

[36] A. Klamt, J. Phys. Chem. 1996, 100, 3349.

[37] G. Scalmani, M. J. Frisch, B. Mennucci, J. Tomasi, R. Cammi, V. Barone, J. Chem. Phys. 2006, 124, 094107.

[38] A. D. Becke, J. Chem. Phys. 1993, 98, 5648-5652.

[39] P. J. Stephens, F. J. Devlin, C. F. Chabalowski, M. J. Frisch, J. Phys. Chem. 1994, 98, 11623-11627. 
[40] Gaussian 09, Revision D.01, Frisch, M. J.; Trucks, G. W.; Schlegel, H. B.; Scuseria, G. E.; Robb, M. A.; Cheeseman, J. R.; Scalmani, G.; Barone, V.; Mennucci, B.; Petersson, G. A.; Nakatsuji, H.; Caricato, M. Li, X.; Hratchian, H. P.; Izmaylov, A. F.; BI, D. J. Gaussian 09, Revision D.01; Gaussian, Inc.: Wallingford CT, 2009

[41] Jmol: an open-source Java viewer for chemical structures in 3D. http://www.jmol.org/.
Received: ((will be filled in by the editorial staff))

Revised: ((will be filled in by the editorial staff) Published online: ((will be filled in by the editorial staff $)$ ) 
Entry for the Table of Contents (Please choose one layout only)

Layout 1:

\section{FULL PAPER}

Let's switch: Introducing a metalvinyl moiety onto a helicene core is shown to be promising, straightforward approach to enhance chiroptical properties and confer multifunctionality on the helicene by endowing redox activity.

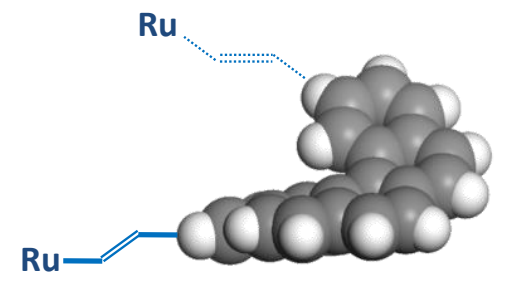

Herein, example Ru-vinylhelicenes are characterized in detail. The extended $\pi$-conjugation between $\mathrm{Ru}$ center(s) and helicene via vinyl bridge determines unique redox chiroptical switching of these systems.

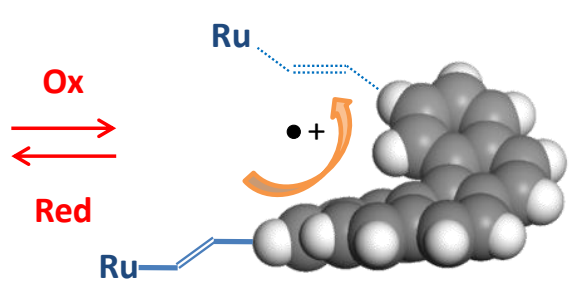

\section{Subject Heading}

Monika Srebro, Emmanuel Anger, Barry Moore, II, Nicolas Vanthuyne, Christian Roussel, Régis Réau, Jochen

Autschbach, * Jeanne Crassous *

\section{घ- $\mathbf{\square}$}

Ruthenium-grafted vinylhelicenes: chiroptical properties and redox switching 
